Article

\title{
Design and Implementation of an Energy-Management System for a Grid-Connected Residential DC Microgrid
}

\author{
Alfredo Padilla-Medina ${ }^{1}$, Francisco Perez-Pinal ${ }^{1}$ (D), Alonso Jimenez-Garibay ${ }^{2}$ (D), \\ Antonio Vazquez-Lopez ${ }^{3}$ and Juan Martinez-Nolasco ${ }^{2, *(D)}$ \\ 1 Departamento de Ingeniería Electrónica, Tecnológico Nacional de México/IT de Celaya, \\ Celaya 38010, Guanajuato, Mexico; alfredo.padilla@itcelaya.edu.mx (A.P.-M.); \\ francisco.perez@itcelaya.edu.mx (F.P.-P.) \\ 2 Departamento de Ingeniería Mecatrónica, Tecnológico Nacional de México/IT de Celaya, \\ Celaya 38010, Guanajuato, Mexico; alonso.jimenez@itcelaya.edu.mx \\ 3 Departamento de Ingeniería Industria, Tecnológico Nacional de México/IT de Celaya, \\ Celaya 38010, Guanajuato, Mexico; antonio.vazquez@itcelaya.edu.mx \\ * Correspondence: juan.martinez@itcelaya.edu.mx
}

Received: 13 May 2020; Accepted: 3 August 2020; Published: 6 August 2020

check for updates

\begin{abstract}
The design and implementation of an energy-management system (EMS) applied to a residential direct current microgrid $(\mathrm{DC}-\mu \mathrm{G})$ is presented in this work. The proposed residential $\mathrm{DC}-\mu \mathrm{G}$ is designed to provide a maximum power of one kilowatt by using two photovoltaic arrays (PAs) of $500 \mathrm{~W}$, a battery bank (BB) of $120 \mathrm{~V}-115 \mathrm{Ah}$, a supercapacitor module of $0.230 \mathrm{~F}$ and a bidirectional DC-AC converter linked to the AC main grid (MG). The EMS works as a centralized manager and it defines the working operation mode for each section of the DC- $\mu \mathrm{G}$. The operation modes are based on: (1) the DC-link bus voltage, (2) the generated or demanded power to each section of the DC- $\mu \mathrm{G}$ and (3) the BB's state of charge. The proposed EMS-during the several working operation modes and at the same time-can obtain the maximum energy from the PAs, reduce the energy consumption from the main grid and keep the DC-link bus voltage inside a range of $190 \mathrm{~V} \pm 5 \%$. The EMS and local controllers are implemented by using LabVIEW and NI myRIO-1900 platforms. Moreover, experimental results during connection and disconnection of each DC- $\mu \mathrm{G}$ sections and different on-the-fly transitions are reported, these results focus on the behavior of the DC bus, which shows the DC bus robustness and stability. The robustness of the DC- $\mu \mathrm{G}$ is demonstrated by maintaining a balance of energy between the sources and loads connected to the DC bus under different scenarios.
\end{abstract}

Keywords: energy-management system; residential DC microgrid; grid-connected; photovoltaic array; embedded system

\section{Introduction}

Power consumption increase and the never-ending industrial demand on electrical energy have resulted in a higher requirement of electrical energy generation worldwide and therefore, a depletion of conventional generation resources, such as fossil fuels. On the other hand, renewable energies are still facing issues for massive generation and supply due to its unpredictable nature. These challenges have allowed a development in efficient technologies for energy conversion. An alternative to cope this situation is the use of renewable energy sources; however, its' massive introduction and sustainable production are still open challenges to be satisfied. One alternative to solve these issues is 
the distributed generation techniques sourced by renewable energy which require efficient and highly reliable power management schemes in microgrids [1].

Among the investigations carried out on energy-management systems (EMSs) in microgrids $(\mu \mathrm{Gs})$ there are different approaches. In [2] a theoretical reference is presented for the optimization and operation of $\mu \mathrm{Gs}$ considering the impact of energy storage, the integration of renewable energy sources and the request for an answer for a case in Hong Kong. In [3] a study of interconnected $\mu \mathrm{Gs}$ is presented, focusing on energy commercialization and scheduling strategies considering the local energy consumption (individual $\mu \mathrm{G}$ ), but also on the exchange of energy between $\mu \mathrm{Gs}$, demonstrating a reduction in operating cost up to $13 \%$. In [4] an effective EMS applied in integrated building systems and $\mu \mathrm{Gs}$ is presented, demonstrating that the proposed system has the ability to preserve energy and reduce consumption costs. This EMS considers aspects such as distributed heat generation and characteristics of electrical generation. The results of this research focus on the behavior of the energy of the elements of the $\mu \mathrm{G}$, the frequency and the voltage in response to their proposed master-slave control system, heat flow and temperature. All these studies present results using numeric simulation and focus on the analysis of energy levels between $\mu \mathrm{Gs}$ and the elements that compose them.

An example, of the configuration of a microgrid is a residential direct current microgrid (DC- $\mu \mathrm{G})$ using photovoltaic solar panels as a main energy source. A conventional grid-connected DC- $\mu \mathrm{G}$ is constituted by different elements such as: generators, storage energy devices, loads and the interconnexion device linked to the alternating current (AC) main grid (MG). Usually, those elements are connected to the DC-link through power electronic converters (PECs). In this proposal, the efficiency of two optimization strategies of a DC- $\mu \mathrm{G}$ is evaluated: (1) a centralized EMS that manages the energy in the batteries in order to keep the bus voltage stable; (2) optimization of switching frequency of each converter to improve its efficiency. The authors conclude that both independent strategies increase the efficiency of DC- $\mu \mathrm{G}[5]$.

In [6], the authors carry out a scientific review about control strategies, stability analysis and stabilization techniques implemented in a DC- $\mu \mathrm{G}$, one of their main conclusions is that the local control of the converters is relevant to the integration of a level of control higher than most used in the control techniques that are proportional-integral (PI), proportional-derivative (PD), proportional-integral-derivative (PID) and fuzzy control (FC). Regarding communication between the elements of a DC- $\mu \mathrm{G}$, the authors conclude that three basic control strategies have been widely reported: (1) Decentralized control: the digital communications links are nulled and the electric lines are used as communication channels. Usually, the DC-link voltage demand is used as feedback; (2) Centralized control: the information is generated by different devices, and it is sent to a unique master. In this master, data are processed and sent it back by using different digital communication links; (3) Distributed control: The digital communication channels are implemented between systems and the coordinated control strategies are locally processed.

Lately, there have been reports of EMS applied in DC- $\mu \mathrm{G}$ with good simulation results, and a brief review following the report. Reference [7] reported an isolated DC- $\mu \mathrm{G}$ with a DC-link of $24 \mathrm{~V}$ and connected to different loads (laptop (19 V, $65 \mathrm{~W})$, lighting LED (240 V, $90 \mathrm{~W})$, fan $(48 \mathrm{~V}, 90 \mathrm{~W})$ ) by using appropriate PECs and one active filter. The proposed design facilitates standalone powering of a rural household which need less than $250 \mathrm{~W}$ provided by a PA. Reference [8] proposed a hierarchical controller based on three operation modes, the controller guaranteed the DC-link bus stability for the different operation modes, only numeric results are reported. Considering three modes of operation under six operational situations in terms of load variations, an analysis of operation times is performed for each of the six operational situations under consideration.

Further DC- $\mu \mathrm{G}$ configurations are the ones reported in $[9,10]$. In these proposals, a supercapacitor bank is connected to the DC-link bus by using a bidirectional converter. Additionally, a virtual resistor and capacitor is used as an impedance control loop, between the DC-link and converter. The reported numeric results in MATLAB, showed a good dynamic response, which was more precise compared with previous topologies. However, it lacked practical or at least hardware in the loop (HIL) validation. 
On the other hand, a decentralized power management for an isolated DC- $\mu \mathrm{G}$ was reported in [11]. In this investigation, numeric results were obtained by using SIMULINK the results showed an adaptive $\mathrm{I} / \mathrm{V}$ characteristic as a decentralized control strategy of a hybrid $\mathrm{DC}-\mu \mathrm{G}$ whose structure contains a PA and battery energy storage system and wind turbine generator that can keep the DC-link bus stable even when the energy demand exceeds the maximum power generation. Following this trend, a different isolated $D C-\mu \mathrm{G}$ with six operation modes was controlled by using an energy balance method [12]. In this study, an interesting scheme to control the on-the-fly photovoltaic transitions between modes was reported, which reduced the DC-link bus oscillations. Restrictions of this scheme were the use of only linear loads and a maximum bus variation of $6 \%$.

Another branch of EMS is the development and application of intelligent algorithms. For instance, reference [13] proposed an isolated residential DC- $\mu \mathrm{G}$ controlled by a fuzzy logic EMS. In this work, only SIMULINK numeric results were achieved and the FC is evaluated under two scenarios of a $D C-\mu G$ consisting of PAs, wind turbine, battery bank (BB), fuel cell and diesel generator supplying a typical residential load, the EMS is controlled by a low complexity FC with only 25 fuzzy rules that combine two input variables, the state of battery charge and the power difference between generated power from renewables and load demand $\Delta \mathrm{P}$ represent the power difference between generated power from renewables and load power during day hours. The authors consider their proposal as an economic dispatch problem. A further centralized fuzzy logic proposal was reported in [14]. In this study, an accurate DC-link voltage and current regulation was achieved for a DC- $\mu G$. As a result, authors claimed a cost reduction compared with centralized controllers. Unfortunately, only resistive loads and numeric results were stated. In [15], a low voltage (200 V) grid-connected DC- $\mu$ G with PA and storage unit was reported. In this proposal, a neuronal controller was implemented and behavior in the DC-link was given. Once again, HIL or practical results were missed.

On the other hand, investigations that present experimental tests, [16] proposes a flexible control mechanism to change the operation mode of photovoltaic systems in a $D C-\mu G$, although experimental results were presented, the stability of the DC-link bus was not presented. Study [17] present a multi-condition strategy based on energy management for an isolated DC- $\mu \mathrm{G}$ consisting of a PA, a fuel cell and a BB. This proposal distributes the energy and keeps the DC-link bus voltage stable in different operating conditions that depend on the state of charge $\left(\mathrm{S}^{\circ} \mathrm{C}\right)$ of the batteries, the loads and the power of the PA. To verify the operation of the proposed administration system, an experimental prototype was implemented considering that the results obtained were good.

In [18] the authors proposed a centralized control technique for EMS in an experimental prototype of a DC- $\mu \mathrm{G}$ with a $380 \mathrm{~V}$ bus, this $\mu \mathrm{G}$ is interconnected to the MG through a PEC, which is in charge of EMS, regulating the DC-link bus. LabVIEW software is used to monitor the power of the DC- $\mu \mathrm{G}$. Case studies are presented considering irradiation changes, resistive load, $\mathrm{S}^{\circ} \mathrm{C}$ and power limits. In the quest to improve energy management in a DC- $\mu \mathrm{G}$ with a BB, [19] proposed the use of a fuzzy controller to improve the life cycle of a BB, stabilizing the DC-link bus in a range of $380 \mathrm{~V} \pm 20 \mathrm{~V}$; this system uses LabVIEW software to implement the EMS. LabVIEW is an alternative in EMS design, this is because it has boards for monitoring and control. [20] used the PCI-MIO16-E-4 board to control a three-phase converter which is used to control an induction motor connected in a DC- $\mu$ G with a $600 \mathrm{~V}$ bus, the experimental tests presented used resistive loads. In [21] the authors proposed a power control approach to provide energy management and stabilization of a hybrid DC- $\mu \mathrm{G}$ for transportation applications, the control system was implemented on dSPACE real-time boards. The simulation results shown the effectiveness of the control system to manage the power flows between the supercapacitor, the rectifier and the load; furthermore, the authors found that the experimental results are consistent with the simulations. In [22] a fault-tolerant supervisory controller (FTSC) is proposed, and its effectiveness is evaluated using a hybrid AC/DC $\mu \mathrm{G}$ simulated in MATLAB considering the effects of maximum power derived from possible failures in solar and wind systems, the proposed FTSC considers a procedure to determine the maximum power available under fault conditions and increases the tolerance of the supervisory controller. These faults in solar and wind systems represent 
an unknown dynamic that can be modeled using fuzzy controllers. Consequently, in [23] a control strategy for a hybrid renewable energy sources (HRES) system is proposed using FC systems that contain adaptive rules to obtain better performance from an HRES system evaluated under different load conditions and failures in renewable energy sources.

The previously described state of the art shows that several architectures implemented in hardware have been reported with satisfactory results. However, in author's opinion, some of them are oversimplified and other considers ideal conditions, which are not satisfied in real-life situations. Therefore, this study proposes a methodology for the design and implementation of a EMS that has a global administrator, which defines the operation mode each PEC's controllers inside the DC- $\mu \mathrm{G}$. Both controllers use National Instruments technology; indeed, the embedded EMS was used in an experimental $\mathrm{DC}-\mu \mathrm{G}$ prototype that has two PAs, a BB and a bidirectional DC-AC converter to interconnect it. Experimental tests on DC- $\mu \mathrm{G}^{\prime}$ s behavior with the EMS were performed using electronic loads such as computer equipment, LED lamps and fluorescent lamps focusing on the behavior of the DC-link bus when connecting and disconnecting sources and loads which generate changes in the operating modes of each of the local controllers in charge of manipulating the PECs that make up the DC- $\mu \mathrm{G}$.

The obtained results show stability in the DC-link bus due to the generated disturbances and to changes in the operating modes of the DC- $\mu \mathrm{G}$ components, advantages of this proposed system compared with reported literature is listed to follow. First, results obtained show that it is not necessary to include electrical components to the network for the connection and disconnection of energy sources and real loads. Second, the DC- $\mu \mathrm{G}$ state machine that controls the global manager considers six operating scenarios to stability of the DC bus, taking advantage of the maximum power of the PAs, balancing the energy generated and demanded by the elements that make up the $D C-\mu G$, and take care of the charging and discharging processes of the battery bank, thus increasing their useful life. Third, results presented focus on the behavior of the DC bus when connecting and disconnecting electronic sources and loads used daily, which shows robustness and stability, presenting transitory response times between 4 and $20 \mathrm{~s}$ with variations in voltage on the bus less than $5 \%$. Finally, using the LabVIEW virtual instrumentation software (2015, National Instruments, USA) and the NI myRIO-1900 for the implementation of the global administrator and local controllers has virtues such as the generation of a user-friendly interface, which allows monitoring relevant variables of the DC- $\mu \mathrm{G}$ and modify parameters of the controllers in real time. Additionally, it has flexibility for the quick reconfiguration of the generated controllers, which enables the generation of more complex systems in a short time, adapting embedded systems to new experiments.

This work is organized as follows: In Section 2, the structure of the DC- $\mu \mathrm{G}$ used to evaluate the EMS under different scenarios is described. In Section 3, the control and management system (CMS) is described which establishes the mode of operation for each element of the DC- $\mu \mathrm{G}$ in order to extract the maximum energy from the PVEs. In Section 4, the results obtained are described to verify the behavior of the CMS embedded with the experimental prototype of the DC- $\mu \mathrm{G}$, each of the PVEs was configured with the following parameters: $V_{\mathrm{mpp}}=120 \mathrm{~V}, \mathrm{~V}_{\mathrm{oc}}=130 \mathrm{~V}, \mathrm{I}_{\mathrm{mpp}}=2 \mathrm{~A}$ and $\mathrm{I}_{\mathrm{sc}}=3 \mathrm{~A}$. Section 5 , finally, presents a brief summary and conclusions of the obtained results.

\section{DC Microgrid Structure}

The DC- $\mu \mathrm{G}$ was designed to deal with a maximum power of $1 \mathrm{~kW}$, with a DC-link bus of $190 \mathrm{~V}$. The energy direction between sources and loads is shown with blue color lines Figure 1 and the experimental prototype is shown in Figure 2. The left part of Figure 1 shows two PAs emulated with two Agilent E4360A which were connected to a pair of $600 \mathrm{~W}$ DC-DC boost converters this section as the main energy source. On the other hand, in the right section of Figure 2, a bidirectional DC-AC converter allows to flow energy, in both directions, between the DC- $\mu \mathrm{G}$ to the MG. Additionally, a BB of $115 \mathrm{Ah}$ and $120 \mathrm{~V}$ is connected to the DC-link bus by using a bidirectional buck-boost converter. 
Finally, a supercapacitor bank of $0.230 \mathrm{~F}$ is directly linked to the DC-link bus, without converter, this bank allows to support the DC-link voltage during connection or disconnection of any $\mu \mathrm{G}$ section.

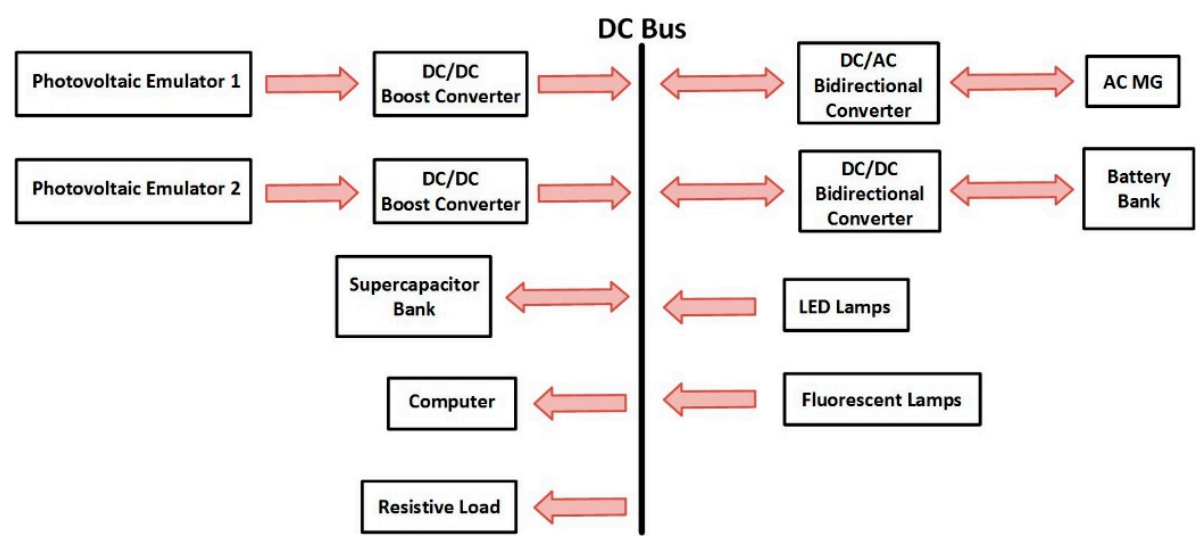

Figure 1. Direct current microgrid $(\mathrm{DC}-\mu \mathrm{G})$ block diagram.

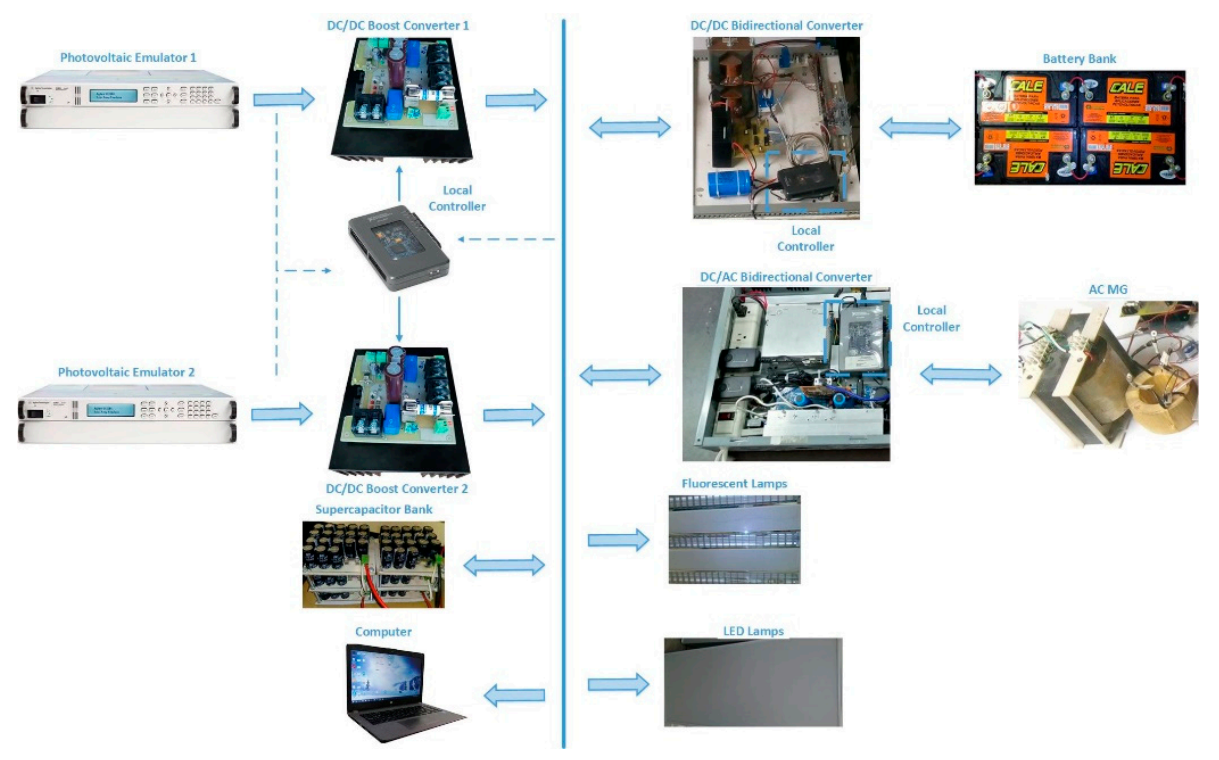

Figure 2. DC- $\mu \mathrm{G}$ experimental test-bed.

The selection of the DC- $\mu \mathrm{G}$ bus voltage level is due to the operating characteristics of the loads connected to the bus, these are conventional electrical loads designed for connection to the AC MG with a universal input voltage range of 100-264 VAC according to manufacturer specifications, the objective of using these loads is to demonstrate that these types of nonlinear loads do not require any type of electrical modification to be connected to the voltage bus of the proposed DC- $\mu \mathrm{G}$. With these considerations, the PECs in charge of transferring energy between the different elements of the DC- $\mu \mathrm{G}$ were designed. It is important to mention that the reported research studies operate with DC buses in operating ranges between $190 \mathrm{~V}$ to $210 \mathrm{~V}[24,25]$.

\subsection{DC-DC Boost Converter}

As mentioned before, the main DC- $\mu \mathrm{G}$ sources, PAs, are two photovoltaic emulators (PVEs), those are connected to a pair of classical boost converters, Figure 3. The boosts converters were designed with a step-up relation of $\mathrm{V}_{\mu \mathrm{G}} \mathrm{V}_{\mathrm{PVE}}=1.5\left(\mathrm{~V}_{\mu \mathrm{G}} \mathrm{DC}\right.$ bus voltage, $\mathrm{V}_{\mathrm{PVE}} \mathrm{PVE}$ voltage) and continuous conduction mode. These specifications allow to achieve $190 \mathrm{~V}$ in the maximum power point (MPP) and buy using [26], with a frequency of $40 \mathrm{kHz}$, the following data were obtained, $\mathrm{L}=107 \mu \mathrm{H}, \mathrm{C}=440 \mu \mathrm{F}$. It 
is necessary to mention that, in order to use of PVEs was required to provide the following parameters: voltage in the maximum power point $\left(\mathrm{V}_{\mathrm{mpp}}\right)$, open-circuit voltage $\left(\mathrm{V}_{\mathrm{oc}}\right)$, current in the maximum power point $\left(\mathrm{I}_{\mathrm{mpp}}\right)$ and short-circuit current $\left(\mathrm{I}_{\mathrm{sc}}\right)$. Additionally, those parameters rely on the $\mu \mathrm{G}^{\prime} \mathrm{s}$ experimental tests.

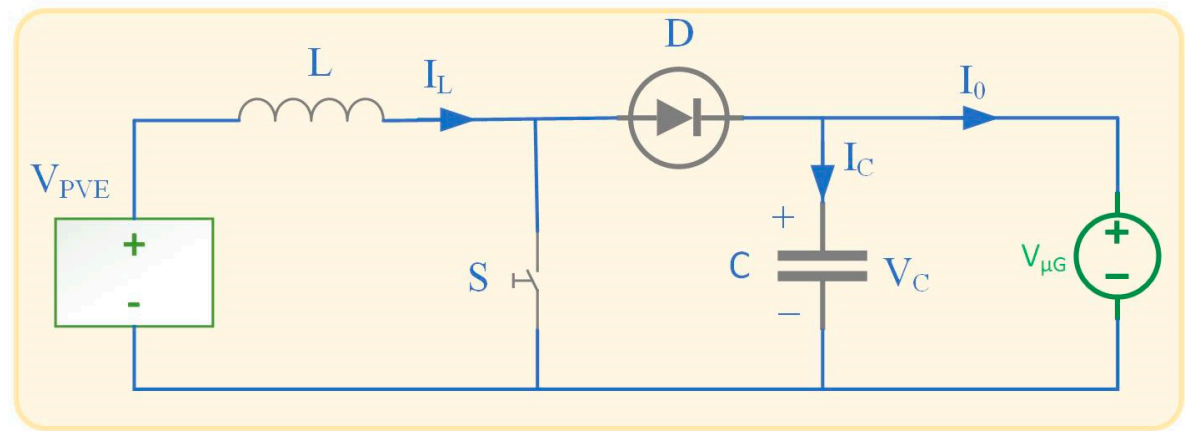

Figure 3. DC-DC boost converter.

\subsection{Bidirectional $D C-A C$ Converter}

Figure 4 shows the designed bidirectional buck-boost converter. During the rectifier operation from MG to the DC-link, this converter provides energy to the DC loads, to the BB or both. On the other hand, during the inverter operation, it provides energy from the DC-link to the MG.

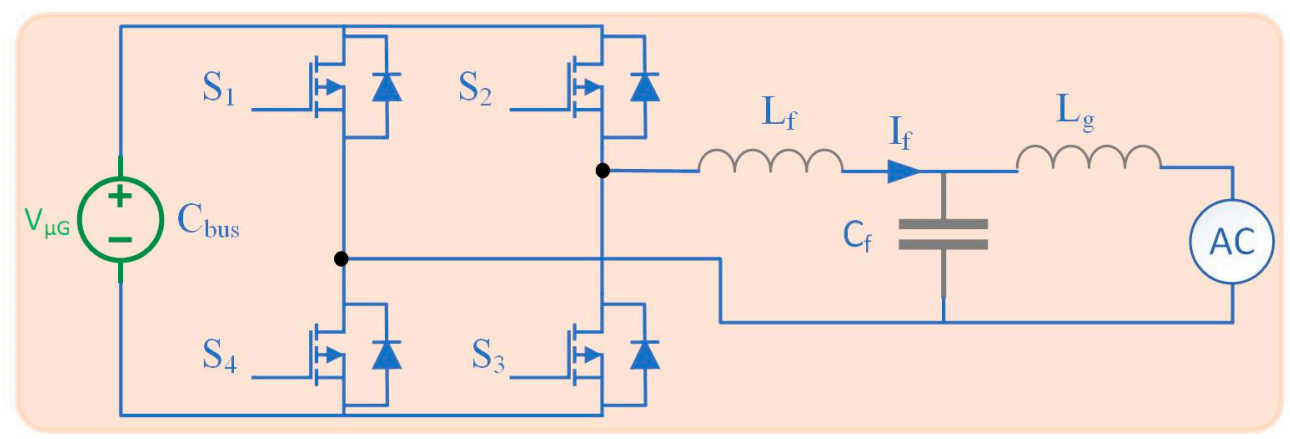

Figure 4. Bidirectional DC-AC converter.

This converter requires a capacitor $C_{\text {bus }}$, to stabilize the DC-link voltage. The minimum capacitance is given by:

$$
C_{\text {bus }}=\frac{\left(4 \mathrm{P}_{\text {out }}\right)\left(\mathrm{t}_{1}\right)}{\mathrm{V}^{2}{ }_{\mu \mathrm{G}, \min }}=308 \mu \mathrm{F},
$$

where $P_{\text {out }}$ represents the output power, $V_{\mu G \text {,min }}$ the minimum $D C$ bus voltage required to transfer energy to the MG and $t_{1}$ the time interval given as

$$
\mathrm{t}_{1}=\frac{1}{4 \mathrm{f}_{\text {grid }}}=4.16 \mathrm{~ms},
$$

where $\mathrm{f}_{\text {grid }}$ is the grid frequency, with a value of $60 \mathrm{~Hz}$. On the AC side, an LCL filter is connected to the midpoints of inverter legs and is used to interface the DC-link to the MG. To design the LCL was followed the Official Mexican Norm (NOM) and the Mexican Electricity Commission (CFE), those are based on IEC 61727:2004. The filtering inductance is obtained as

$$
\mathrm{L}_{\mathrm{f}}=\frac{\left(\mathrm{V}_{\mu \mathrm{G}}-\mathrm{V}_{\mathrm{grid}, \mathrm{pk}}\right) \mathrm{D}}{\mathrm{n} \cdot \Delta \mathrm{I}_{\mathrm{f}} \cdot \mathrm{f}_{\mathrm{sw}}}=\frac{(190-170) \times(0.8)}{(3) \times(0.1) \times(25000)}=2.13 \mathrm{mH} \text {, }
$$


where $n$ represents the number of levels of the inverter $\left(+V_{\mu G},-V_{\mu G}\right.$ and 0$)$, $D$ the duty cycle, $f_{s w}$ the commutation frequency and $\Delta \mathrm{I}_{\mathrm{f}}$ the ripple current. The criteria considered for the design of the filtering inductance is that $\Delta \mathrm{I}_{\mathrm{f}}$ should be $10 \%$ of the nominal value of $\mathrm{I}_{\mathrm{f}}$. The $\mathrm{C}_{\mathrm{f}}$ capacitance was designed to allow the maximum reactive power exchange. In this operation point the value were:

$$
\begin{gathered}
\mathrm{X}_{\mathrm{C}_{\mathrm{f}}} \geq \frac{\mathrm{V}_{\text {grid,max }}^{2}}{\mathrm{P}_{\text {reactive }}}=54 \Omega, \\
\mathrm{C}_{\mathrm{f}} \leq \frac{1}{\omega \cdot \mathrm{X}_{\mathrm{C}_{\mathrm{f}}}}=49 \mu \mathrm{F},
\end{gathered}
$$

The filter resonance frequency, $\mathrm{f}_{\mathrm{res}}$, was given as

$$
\mathrm{f}_{\text {res }}=\frac{1}{2 \pi} \sqrt{\frac{\mathrm{L}_{\mathrm{f}}+\mathrm{L}_{\mathrm{g}}}{\left(\mathrm{L}_{\mathrm{f}}\right)\left(\mathrm{L}_{\mathrm{g}}\right)\left(\mathrm{C}_{\mathrm{f}}\right)}},
$$

where $\mathrm{f}_{\text {res }}$ should be 0.5 times the commutation frequency and 10 times the fundamental frequency of the MG, to avoid any problems related with the resonance state of the LCL filter. This criterion is met by assigning values of $1 \mathrm{mH}$ and $1 \mu \mathrm{F}$ to $\mathrm{Lg}_{\mathrm{g}}$ and $\mathrm{C}_{\mathrm{f}}$, respectively, and considering a $2 \%$ of the value obtained for $\mathrm{C}_{\mathrm{f}}$ [27]. As a result, a $\mathrm{f}_{\text {res }}$ of $6.1 \mathrm{kHz}$ was obtained.

\subsection{Bidirectional DC-DC Converter}

A traditional buck-boost DC-DC converter was used, and it is shown in Figure 5. In this kind of converter, the energy direction is controlled by firing $S_{1}$ and $S_{2}$. In the step-down operation, DC-link to $\mathrm{BB}, \mathrm{S}_{1}$ is switching and $\mathrm{S}_{2}$ is open. During the step-up operation, BB to DC-link, $\mathrm{S}_{1}$ is open and $\mathrm{S}_{2}$ is switching. The BB was made by connecting ten deep-cycle batteries CALE-SOLAR (CL-31 T/S-190 M) in series, each one with a voltage of $12 \mathrm{~V}$ and $115 \mathrm{Ah}$. Additionally, a passive equalization method was employed to guarantee the voltage balance between cells [28]. Table 1 shows the parameters to design the bidirectional DC-DC converter; Table 2 shows the determined parameters.

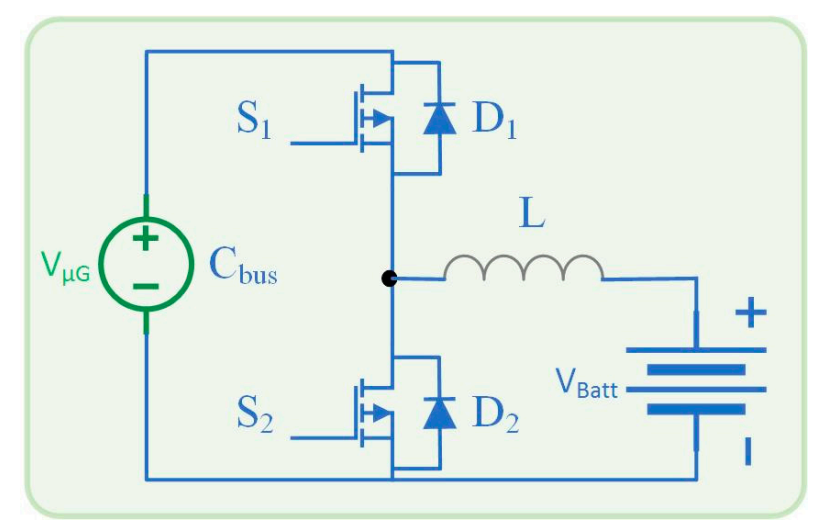

Figure 5. Bidirectional DC-DC converter. 
Table 1. Bidirectional DC-DC converter parameters.

\begin{tabular}{cc}
\hline Design Feature & Value \\
\hline Rated power & $1000 \mathrm{~W}$ \\
\hline Maximum low voltage & $135 \mathrm{~V}$ \\
\hline Minimum low voltage & $100 \mathrm{~V}$ \\
\hline Maximum high voltage & $180 \mathrm{~V}$ \\
\hline Minimum high voltage & $200 \mathrm{~V}$ \\
\hline Switching frequency & $30 \mathrm{kHz}$ \\
\hline Current ripple in the inductor & $10 \%$ \\
\hline Voltage ripple on the high side & $5 \%$ \\
\hline
\end{tabular}

Table 2. Passive elements.

\begin{tabular}{cc}
\hline Elements & Value \\
\hline Inductor $(\mathrm{L})$ & $11.11 \mathrm{mH}$ \\
\hline Low voltage capacitor $\left(\mathrm{C}_{1}\right)$ & $12.50 \mu \mathrm{F}$ \\
\hline High voltage capacitor $\left(\mathrm{C}_{2}\right)$ & $157.92 \mu \mathrm{F}$ \\
\hline
\end{tabular}

\subsection{Load Description}

To evaluate the system under different scenarios, linear and nonlinear loads were used. A resistive load of $600 \Omega$ was utilized as a linear load. On the contrary, three different nonlinear loads were used. The first one was a set of seven LED lamps of $23 \mathrm{~W}$ each one; the second was a group of four Louver light system with three fluorescent lamps of $28 \mathrm{~W}$ T5 each one (those included an electronic ballast); finally, a laptop with a maximum power of $300 \mathrm{~W}$ was employed.

\section{Control and Management System}

The proposed CMS consist of a general administrator and independent controllers, which operates different $\mu G^{\prime}$ s systems. The general block system of the $\mu \mathrm{G}$ is shown in Figure 6 . The black color represents the $\mu \mathrm{G}^{\prime}$ s systems and the blue color the different local controllers. Additionally, the global controller is shown in red color. More details about the different working modes and operation of the $\mathrm{DC}-\mu \mathrm{G}$ are given in the following sections.

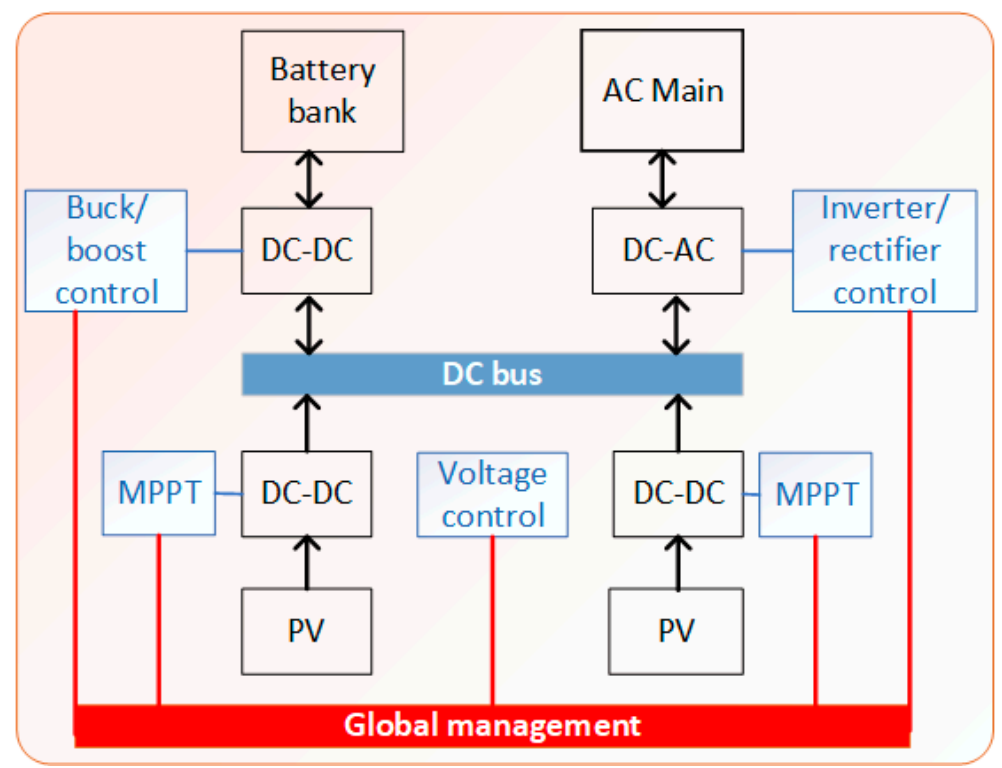

Figure 6. General block system. 


\subsection{Global Management Controller}

The global management controller (GMC) operates with the following six hierarchical scenarios: (1) to maintain the DC-link bus voltage in an operation range of $190 \mathrm{~V} \pm 5 \%$, (2) to consume the maximum energy from the PVE (to reduce the energy coming from the MG), (3) in the case of low load energy consumption and over generated energy from the PVE, the remained energy is stored in the $\mathrm{BB}$, (4) in the case of full charge of the BB or BB discharge, the generated energy is send to the MG, (5) in the case that the load's consumption is bigger than the generated energy from the PVE, the energy difference will be provided by the MG and (6) energy from BB will be used only when the MG is not available or in the case that the generated energy from the PVE and the MG are not enough to cope the demanded load energy.

These scenarios were considered for the design of the GMC in order to keep the DC bus stable, if the bus destabilizes or goes out of the established range, the connected loads could be damaged. On the other hand, it is of utmost importance to make the most of the renewable energy source that MG has. In addition, to defining the energy exchange between the BB and the MG loads, the cost of electrical energy was considered. It is more expensive to transfer energy to the BB than to the MG. Reason why, if there is a surplus of photovoltaic energy, this energy will be stored in the BB and not in the MG. Otherwise, if the loads connected to the DC bus demand more energy than that generated by the PVEs, the missing energy will be taken from the MG and not from the BB. Finally, for the BB charging and discharging process, it is considered that the processes must be completed to take care of the BB's useful life.

It can be noticed that the GMC works as a function of the DC-link bus voltage and the working operation mode of each $\mu \mathrm{G}$ section. During the startup, the PVEs are turned on and those work in the voltage control (VC) mode, in this period, the BB and the MG are turned off. Once the system reaches the steady state, the different loads are connected.

If the demanded load energy is greater than the generated by the PVEs, the DC-link voltage will decrease, in this situation if the voltage reaches a minimum of $183 \mathrm{~V}(2 \mathrm{~V}$ before the critical value of $180.5 \mathrm{~V}$ ), the GMC changes the PVEs controller to a maximum power point tracking (MPPT), and it obtains the energy difference from the DC-AC rectifier. As a result, the DC-link voltage is stabilized and the load energy demand is handled. This operation mode is also used if the energy generated by the PVEs is not enough to supply the energy demanded by the loads connected to the bus. However, this operation mode can be changed if the BB is chosen to cope the energy difference or during lack of solar or MG energy.

On the other hand, if the $\mu \mathrm{G}$ is in steady state, with the PVEs working in VC mode, and the demanded power by loads in less than $80 \%$ of the DC-link maximum capacity, the GMC monitors the $S^{\circ} \mathrm{C}$ of the $\mathrm{BB}$ and the MG with the main aim to change the PVE's operation mode to MPPT and send energy to the BB or the MG. In other words, the energy sent to the BB or the MG is the difference energy generated from the PVEs and the one demanded by loads.

If the BB is depleted or in charging mode, with a light load and the PVE energy is not available, the energy to charge the BB is obtained from the bidirectional DC-DC converter. On the contrary, if the BB is charged, with a light load and the PVE energy is available, the energy is sent to the MG by using the bidirectional DC-DC converter. Figure 7 shows the state machine diagram used in the GMC and Tables 3-7 show the transitions defined between states. Figure 8 presents the flow diagram of the behavior of the GMC. This diagram illustrates the priorities of the GMC. These priorities are based on the six hierarchical scenarios described at the beginning of this section. The priority of the GMC algorithm is to keep the DC bus voltage level within the established range, to extract the maximum power from the PVEs, if the energy demanded by the loads is greater than that generated by the PVEs, the missing energy is taken from the $M G$, if the $M G$ is not available the energy is drawn from the $B B$. In the event that the energy demanded by the loads is less than that generated by the PVEs, the excess energy will be transferred to the $\mathrm{BB}$, if the $\mathrm{BB}$ is charged or in the process of discharge, this energy will be transferred to the MG. 


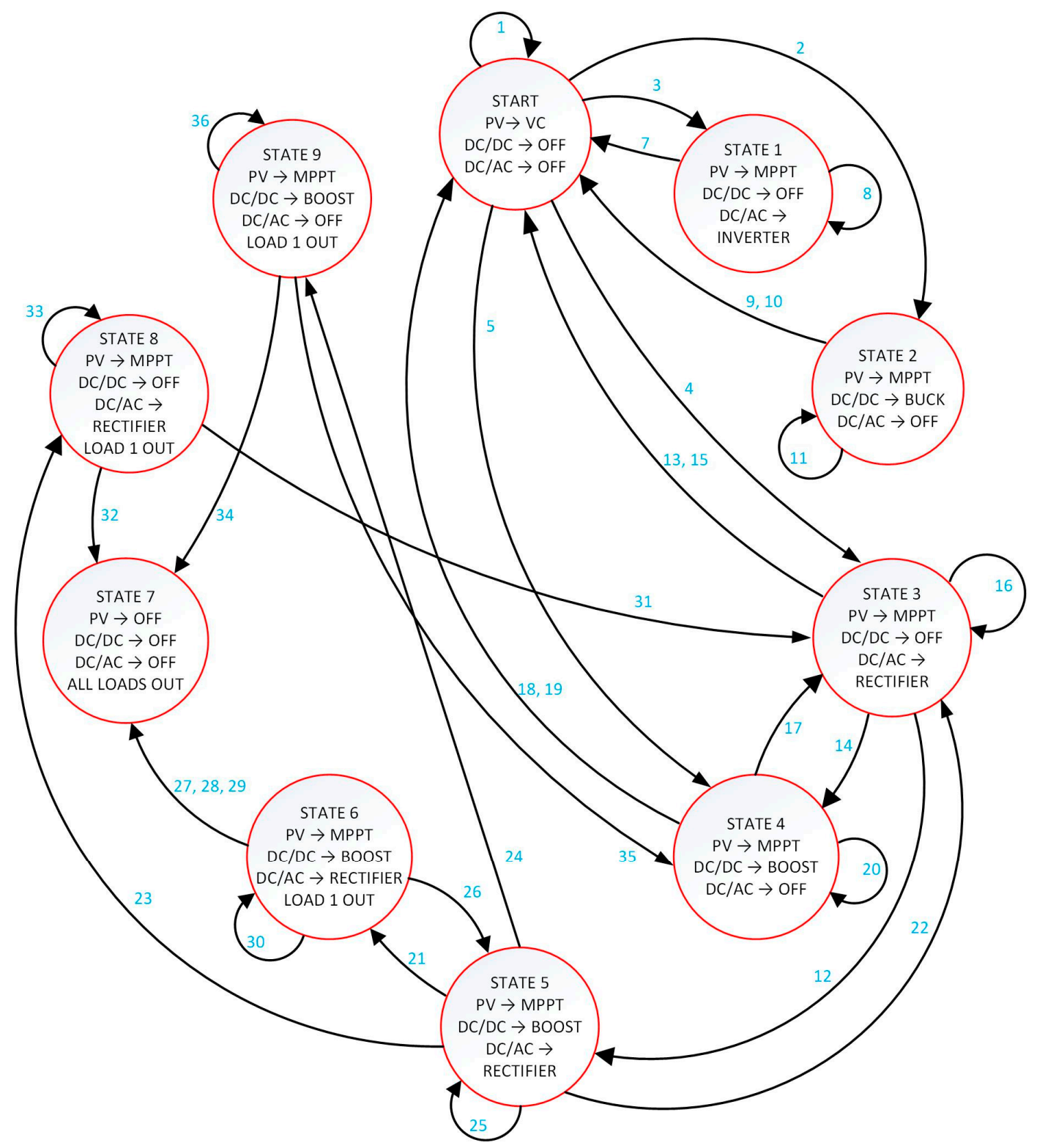

Figure 7. Global management controller (GMC) state machine diagram.

Table 3. GMC START transitions.

\begin{tabular}{|c|c|c|c|c|c|c|c|c|c|c|}
\hline \multicolumn{5}{|c|}{ INPUTS } & \multicolumn{2}{|c|}{ STATES } & \multicolumn{4}{|c|}{ OUTPUTS } \\
\hline Condition & $n$ Vbus & PV Power & MG & Battery & Current State & Next State & PV & $\mathrm{DC} / \mathrm{DC}$ & DC/AC & Loads \\
\hline 1 & $185-195 \mathrm{~V}$ & $>800 \mathrm{~W}$ & - & - & START & START & $\mathrm{VC}$ & OFF & OFF & ON \\
\hline 2 & $188-192 \mathrm{~V}$ & $<800 \mathrm{~W}$ & - & CHARGE & START & STATE 2 & MPPT & BUCK & OFF & ON \\
\hline 3 & $188-192 \mathrm{~V}$ & $<800 \mathrm{~W}$ & AVAILABLE & - & START & STATE 1 & MPPT & OFF & INVERTER & ON \\
\hline 4 & $<183 \mathrm{~V}$ & $>800 \mathrm{~W}$ & AVAILABLE & - & START & STATE 3 & MPPT & OFF & RECTIFIER & ON \\
\hline 5 & $<183 \mathrm{~V}$ & $>800 \mathrm{~W}$ & NOT & DISCHARGE & START & STATE 4 & MPPT & BOOST & OFF & ON \\
\hline 6 & $<180$ & - & NOT & WITHOUT & START & $\begin{array}{l}\text { STATE } 7 \\
\end{array}$ & OFF & OFF & OFF & OUT \\
\hline
\end{tabular}


Table 4. GMC transitions in STATE 1 and 2.

\begin{tabular}{ccccccccccc}
\hline & \multicolumn{3}{c}{ INPUTS } & \multicolumn{4}{c}{ STATES } & \multicolumn{3}{c}{ OUTPUTS } \\
\hline \multicolumn{1}{c}{ Condition } & Vbus & PV Power & MG & Battery & Current State & Next State & PV & DC/DC & DC/AC & Loads \\
\hline 7 & $185-195 \mathrm{~V}$ & - & $<100 \mathrm{~W}$ & - & STATE 1 & START & VC & OFF & OFF & ON \\
\hline 8 & $185-195 \mathrm{~V}$ & - & - & - & STATE 1 & STATE 1 & MPPT & OFF & INVERTER & ON \\
\hline 9 & $>198 \mathrm{~V}$ & - & - & CHARGED & STATE 2 & START & VC & OFF & OFF & ON \\
\hline 10 & $185-195 \mathrm{~V}$ & - & - & $<50 \mathrm{~W}$ & STATE 2 & START & VC & OFF & OFF & ON \\
\hline 11 & $185-195 \mathrm{~V}$ & - & - & - & STATE 2 & STATE 2 & MPPT & BUCK & OFF & ON \\
\hline
\end{tabular}

Table 5. GMC transitions in STATE 3 and 4.

\begin{tabular}{ccccccccccc}
\hline & \multicolumn{3}{c}{ INPUTS } & \multicolumn{4}{c}{ STATES } & \multicolumn{3}{c}{ OUTPUTS } \\
\hline Condition & Vbus & PV Power & MG & Battery & Current State & Next State & PV & DC/DC & DC/AC & Loads \\
\hline 12 & $<183 \mathrm{~V}$ & $>800 \mathrm{~W}$ & $>800 \mathrm{~W}$ & DISCHARGE & STATE 3 & STATE 5 & MPPT & BOOST & RECTIFIER & ON \\
\hline 13 & $>198 \mathrm{~V}$ & - & $<100 \mathrm{~W}$ & - & STATE 3 & START & VC & OFF & OFF & ON \\
\hline 14 & $<183 \mathrm{~V}$ & - & NOT & DISCHARGE & STATE 3 & STATE 4 & MPPT & BOOST & OFF & ON \\
\hline 15 & $<183 \mathrm{~V}$ & - & NOT & NOT & STATE 3 & START & VC & OFF & OFF & ON \\
\hline 16 & $185-195 \mathrm{~V}$ & - & - & - & STATE 3 & STATE 3 & MPPT & OFF & RECTIFIER & ON \\
\hline 17 & $188-192 \mathrm{~V}$ & - & AVAILABLE & - & STATE 4 & STATE 3 & MPPT & OFF & RECTIFIER & ON \\
\hline 18 & $>198 \mathrm{~V}$ & - & - & - & STATE 4 & START & VC & OFF & OFF & ON \\
\hline 19 & $<183 \mathrm{~V}$ & - & - & WITHOUT & STATE 4 & START & VC & OFF & OFF & ON \\
\hline 20 & $185-195 \mathrm{~V}$ & - & NOT & DISCHARGE & STATE 4 & STATE 4 & MPPT & BOOST & OFF & ON \\
\hline
\end{tabular}

Table 6. GMC transitions in STATE 5 and 6.

\begin{tabular}{ccccccccccc}
\hline & \multicolumn{1}{c}{ INPUTS } & \multicolumn{1}{c}{ STATES } & \multicolumn{3}{c}{ OUTPUTS } \\
\hline Condition & Vbus & PV Power & MG & Battery & Current State & Next State & PV & DC/DC & DC/AC & Loads \\
\hline 21 & $<183 \mathrm{~V}$ & $>800 \mathrm{~W}$ & $>800 \mathrm{~W}$ & $>800 \mathrm{~W}$ & STATE 5 & STATE 6 & MPPT & BOOST & RECTIFIER & OUT \\
\hline 22 & $>198 \mathrm{~V}$ & - & - & - & STATE 5 & STATE 3 & MPPT & OFF & RECTIFIER & ON \\
\hline 23 & $<183 \mathrm{~V}$ & - & - & WITHOUT & STATE 5 & STATE 8 & MPPT & OFF & RECTIFIER & OUT \\
\hline 24 & $<183 \mathrm{~V}$ & - & NOT & - & STATE 5 & STATE 9 & MPPT & BOOST & OFF & OUT \\
\hline 25 & $185-195 \mathrm{~V}$ & - & - & - & STATE 5 & STATE 5 & MPPT & BOOST & RECTIFIER & ON \\
\hline 26 & $>198 \mathrm{~V}$ & - & - & - & STATE 6 & STATE 5 & MPPT & BOOST & RECTIFIER & ON \\
\hline 27 & $<180 \mathrm{~V}$ & $>800 \mathrm{~W}$ & $>800 \mathrm{~W}$ & $>800 \mathrm{~W}$ & STATE 6 & STATE 7 & OFF & OFF & OFF & OUT \\
\hline 28 & $<180 \mathrm{~V}$ & - & NOT & - & STATE 6 & STATE 7 & OFF & OFF & OFF & OUT \\
\hline 29 & $<180 \mathrm{~V}$ & - & - & WITHOUT & STATE 6 & STATE 7 & OFF & OFF & OFF & OUT \\
\hline 30 & $185-195 \mathrm{~V}$ & - & - & - & STATE 6 & STATE 6 & MPPT & BOOST & RECTIFIER & OUT \\
\hline
\end{tabular}

Table 7. GMC transitions in STATE 8 and 9.

\begin{tabular}{ccccccccccc}
\hline & & INPUTS & \multicolumn{4}{c}{ STATES } & \multicolumn{4}{c}{ OUTPUTS } \\
\hline Condition & Vbus & PV Power & MG & Battery & Current State & Next State & PV & DC/DC & DC/AC & Loads \\
\hline 31 & $>198 \mathrm{~V}$ & - & - & - & STATE 8 & STATE 3 & MPPT & OFF & RECTIFIER & ON \\
\hline 32 & $<183 \mathrm{~V}$ & - & NOT & - & STATE 8 & STATE 7 & OFF & OFF & OFF & OUT \\
\hline 33 & $185-195 \mathrm{~V}$ & - & - & - & STATE 8 & STATE 8 & MPPT & OFF & RECTIFIER & OUT \\
\hline 34 & $<183 \mathrm{~V}$ & - & - & WITHOUT & STATE 9 & STATE 7 & OFF & OFF & OFF & OUT \\
\hline 35 & $>198 \mathrm{~V}$ & - & - & - & STATE 9 & STATE 4 & MPPT & BOOST & OFF & ON \\
\hline 36 & $185-195 \mathrm{~V}$ & - & - & - & STATE 9 & STATE 9 & MPPT & BOOST & OFF & OUT \\
\hline
\end{tabular}




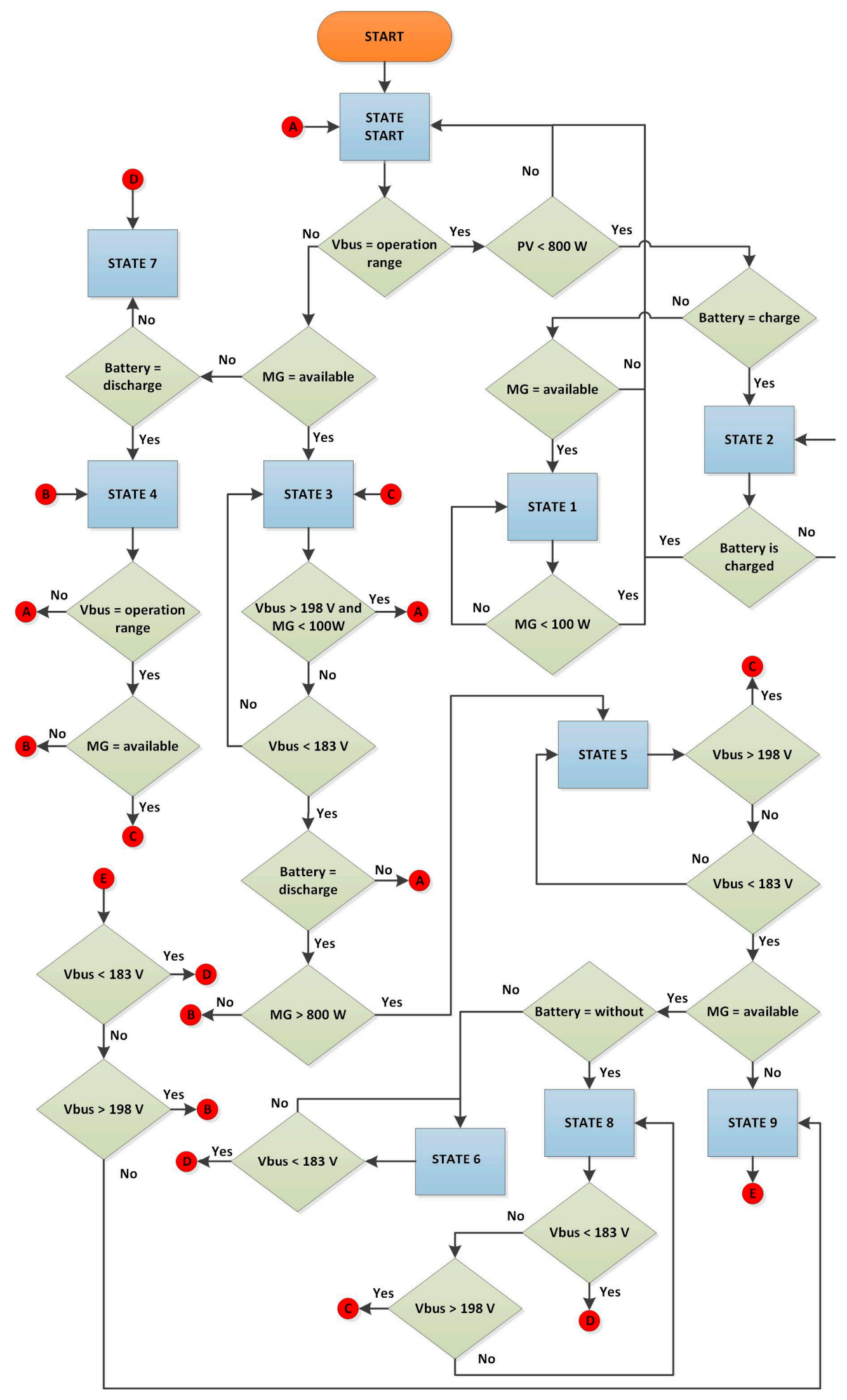

Figure 8. GMC flow diagram. 
The state machine diagram used in $\mu \mathrm{G}$ has ten states, which are listed to follow: START, STATE 1, STATE 2, STATE 3, STATE 4, STATE 5, STATE 6, STATE 7, STATE 8 and STATE 9 . For the overall states, there are defined three main systems: the PVE (PV), the BB DC-DC converter (DC-DC) and the bidirectional converter connected to the MG (DC-AC). For instance, if the GMC is in the START mode, the PV works in voltage control mode (VC), the DC-DC is turned off (OFF) and the DC-AC is also turned off (OFF). Another example is STATE 6, the PV works in the MPPT, the DC-DC as BOOST and the DC-AC as RECTIFIER.

Tables 3-7 show the states transition tables; these have a section of entries that define the conditions for changing from the current state to the next. These inputs are the following signals that were monitored in the $\mu \mathrm{G}$ : the bus voltage level (Vbus), the power generated by the PVE (PV Power), the condition of the MG (MG) and the condition of the BB (Battery). Tables have an output section that defines the operation mode of the PECs and the condition of the local loads connected to the DC bus, these operation modes are the same as those defined in the state machine of Figure 7. For example, when the current state is START, if condition 1 is met, the next state will be START. In this condition Vbus must be greater than $185 \mathrm{~V}$ and less than $195 \mathrm{~V}$, the PV Power must be greater than $800 \mathrm{~W}$, here the MG and Battery status are not considered. In condition 12, Vbus must be less than $183 \mathrm{~V}$, the PV Power must be greater than $800 \mathrm{~W}$, just like the power extracted from the MG (MG), in addition Battery must be in the discharge process.

\subsection{Local Controllers}

The GMC defines the operation mode of each of the local controllers. While these are responsible for generating the control signals that are used in each of the PECs that make up the $\mu \mathrm{G}$. The following describes the embedded control systems designed to keep the system stable.

The DC-DC boost converters connected to the PVEs have two operation modes: (1) the VC mode, and (2) the MPPT mode. In VC mode, a classic PI controller is responsible for maintaining the output voltage of the DC-DC converter (DC bus voltage) at a level of $190 \mathrm{~V}$. This control mode only works when the BB and MG do not supply or extract power to the DC bus. Figure 9 illustrates the converter diagram with the PI controller; this controller monitors the converter output voltage level $\left(\mathrm{V}_{\mu \mathrm{G}}\right)$ by performing corrective actions to eliminate the effects generated by system disturbances (connection and disconnection of loads to the bus of DC).

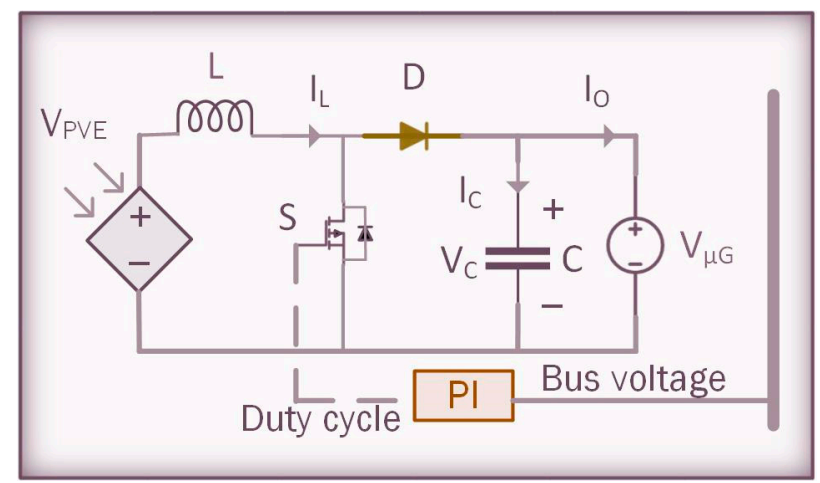

Figure 9. Voltage control (VC) for the boost converter.

The operating point on the characteristics of the PVE module primarily depends on the impedance matching of the PVE module regarding the connected load. A DC-DC converter between the PVE module and the DC bus acts as an interface to operate at MPP by changing the duty cycle of the converter generated by the MPPT controller. In the MPPT operation mode, the boost converters extract the maximum power of the PVEs using the perturb and observe $(\mathrm{P \& O})$ control algorithm illustrated in Figure 10. The conventional P\&O MPPT algorithm is developed based on the slope $\left(\mathrm{d}_{\mathrm{P}} / \mathrm{d}_{\mathrm{V}}\right)$ variation on the P-V characteristics of the PVE module [29]. In this algorithm, an initial value of the duty cycle 
is first defined, then the voltage and current of the PVE $\left(\mathrm{V}_{\mathrm{PVE}}\right.$ and $\left.\mathrm{I}_{\mathrm{PVE}}\right)$ are measured to calculate its supplied power, once the value of the current power $\left(\mathrm{P}_{\mathrm{NEW}}\right)$ is known, it is compared with the power obtained in the past iteration $\left(\mathrm{P}_{\mathrm{PRE}}\right)$, the current value of the duty cycle $\left(\mathrm{D}_{\mathrm{NEW}}\right)$ is also compared and is compared with the previous value of the same ( $\left.\mathrm{D}_{\mathrm{PRE}}\right)$, based on these comparisons an increase is defined (Duty + ) or a decrease (Duty-) in the duty cycle; with this new value of the duty cycle the process is repeated, always seeking to increase the value of the power supplied by the PVE. Figure 11 shows the diagram of the converter with the MPPT controller. The controller modifies the duty cycle of the power switch and monitors the changes in the voltage and current of the PVEs, always looking for an increase in the power extracted from the PVEs.

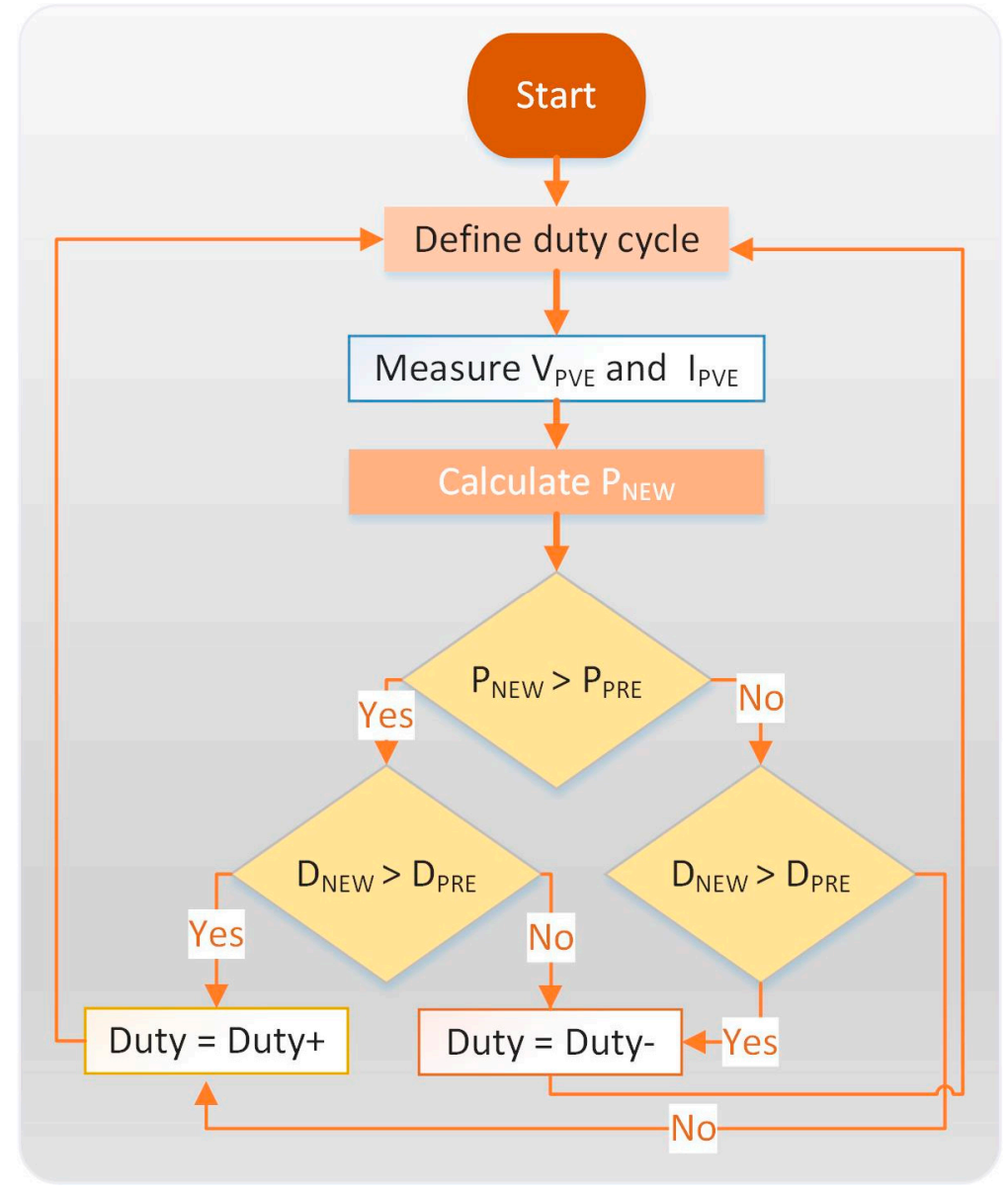

Figure 10. Perturb and observe $(\mathrm{P} \& \mathrm{O})$ control algorithm.

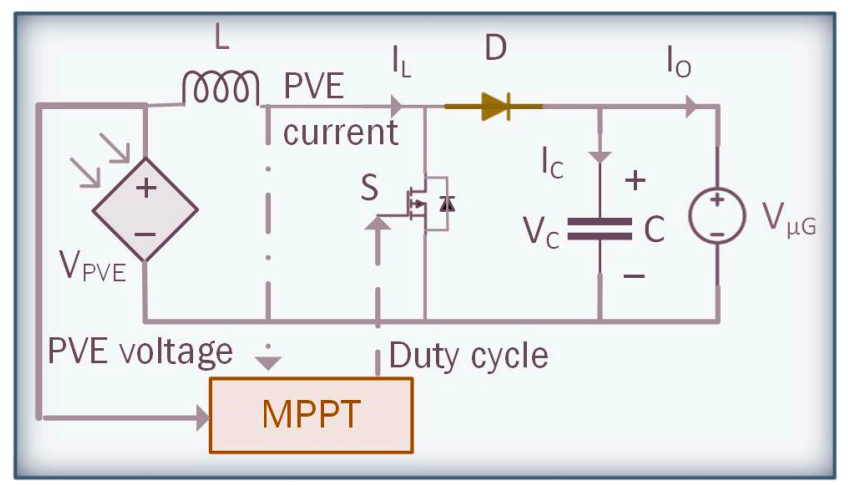

Figure 11. Maximum power point tracking (MPPT) control system diagram. 
The bidirectional DC-AC converter used to interconnect the DC- $\mu \mathrm{G}$ with the MG can operate as a rectifier (transferring energy from the MG to the loads connected to the DC bus) or as an inverter (transferring energy from the DC bus to the MG). The block diagram of the control system implemented for the converter when operating as an inverter is presented in Figure 12. This controller has a PI control action in charge of defining the amplitude of the high frequency triangular signal based on the voltage level of the DC bus, thereby modifying the amount of energy that is transferred to the MG. If the DC bus suffers a voltage drop, a reduction in the amplitude of the triangular signal is generated causing a decrease in the energy transferred to the MG and thus causing an increase in the bus voltage level. In case the bus suffers a voltage overcharge, the amplitude of the triangular signal is increased generating a surge in the energy that is transferred to the MG, thereby lessening the voltage level of the DC bus.

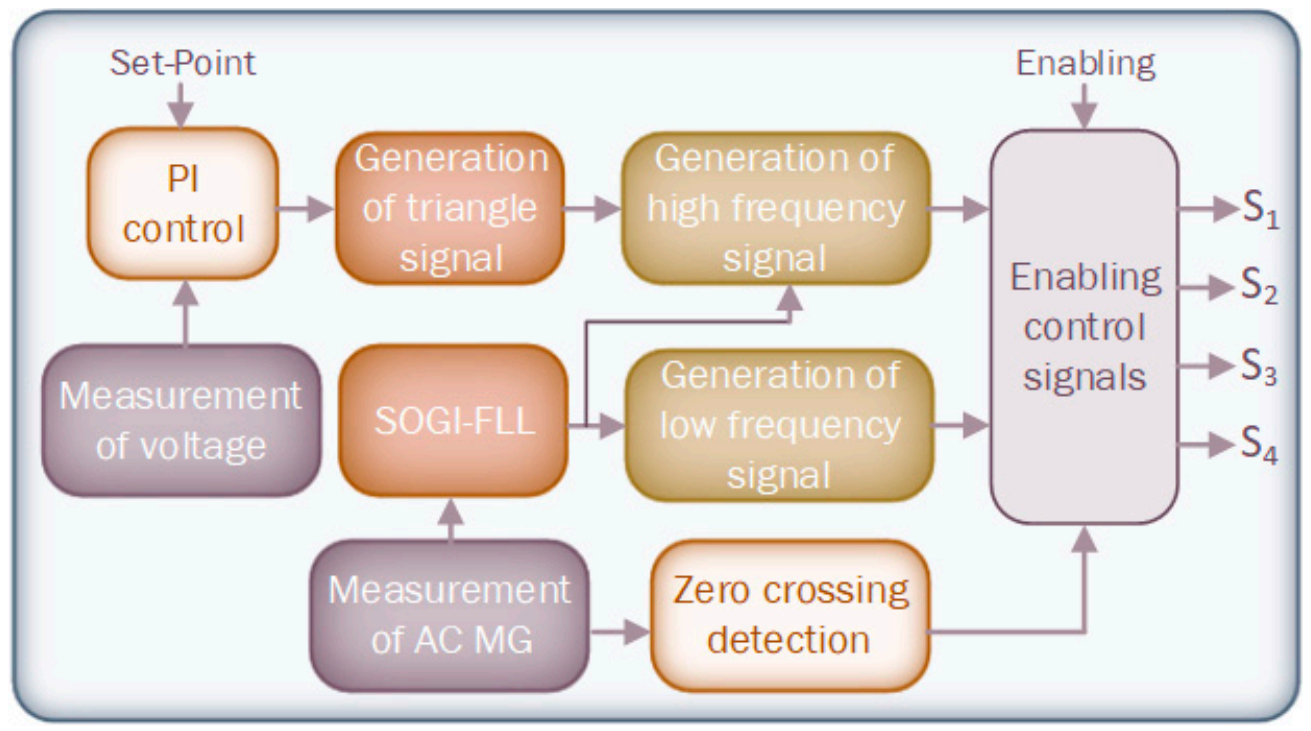

Figure 12. Control algorithm diagram for inverter.

The converter diagram with the controller is shown in Figure 13. The synchronization between the signal generated by the inverter and the MG is performed by the zero crossing detection modules and the second-order generalized integrators with frequency-locked loop (SOGI-FLL) algorithm, this when determined by the GMC. The control signals of the four switches of the complete bridge inverter are generated by comparing the output signal of the SOGI-FLL block with the triangular signal of $25 \mathrm{kHz}$ frequency.

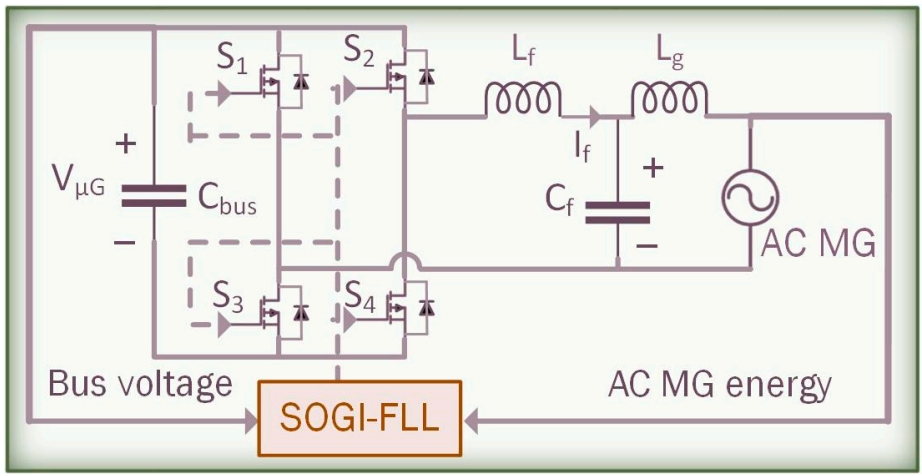

Figure 13. Control for DC-AC converter working as an inverter. 
When the DC-AC bidirectional converter works as a rectifier, the control system is carried out with a classic PI controller, which is responsible for stabilizing the bus voltage level at $190 \mathrm{~V}$ by increasing or decreasing the amplitude of the high frequency triangular signal $f_{s}$ which is compared with the low frequency sine wave signal $\mathrm{u}(\mathrm{t})$ as illustrated in Figure 14.

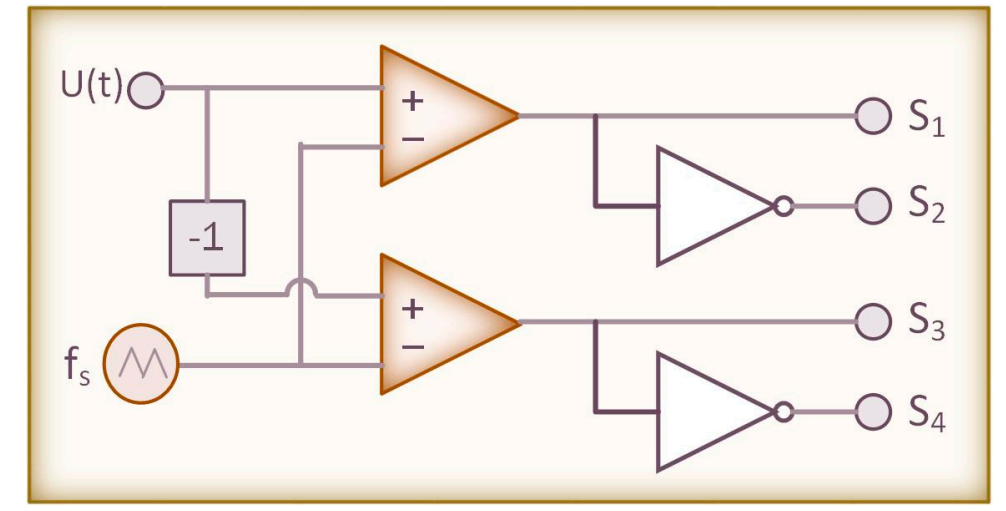

Figure 14. Control for the DC-AC converter working as a rectifier.

The bidirectional DC-DC converter used to interconnect the DC bus with the BB is controlled by a PI controller similar to that used for VC in the PVE converter (Figure 9). This control system has three modes of operation defined by the GMC based on the status of the PVEs, the MG, the electronic loads connected to the DC bus and the electrical charge status of the BB.

(1) Battery charging: The PVEs work with the algorithm for the MPPT and the bidirectional DC-DC converter as a buck transferring power to the BB, while the MG is disabled. The controller operates based on the voltage level of the DC bus. If the voltage level increases, the energy transferred to the BB increases; otherwise, if the voltage level decreases, the energy transferred to the BB decreases;

(2) Battery charging: The PVEs work with the MPPT algorithm, the bidirectional DC-AC converter operates as a rectifier by transferring power from the MG to the loads connected to the DC bus. In this operation mode, it is possible to transfer power from the MG to the $\mathrm{BB}$, the bidirectional DC-DC converter works as a buck. For the control of the energy that is transferred to the BB, the controller operates with the electric current that is transferred to the BB. This electric current is defined by the power demanded from the DC-AC converter before transferring power to the $\mathrm{BB}$, caring not to exceed the maximum capacity of the DC-AC converter designed to work at $1 \mathrm{~kW}$;

(3) Battery discharge: The PVEs work with the algorithm for the MPPT, the bidirectional DC-DC converter functions as a boost transferring power from the BB to the loads connected to the bus, while the MG is disabled. The controller operates based on the voltage level of the DC bus. If the voltage level decreases, the energy transferred from the BB to the DC bus increases; otherwise, if the voltage level increases, the energy transferred decreases.

The previously described cases were defined based on the following BB operating criteria: (1) the BB charging and discharging process must always be completed, (2) the constant current charging process ends until the $\mathrm{BB}$ takes a value of maximum voltage of $135 \mathrm{~V}$ (if the energy generated is not enough to transfer energy to the BB at constant current the available energy is transferred to the $\mathrm{BB}$ ), (3) the constant voltage charging process ends when the current that is injected into the BB is less than $0.5 \mathrm{~A}$ and (4) the discharge process ends when the battery voltage is $100 \mathrm{~V}$. It is important to mention that the bidirectional power converter used in the BB has a maximum capacity of $1 \mathrm{~kW}$, for this reason, the maximum current that can be extracted or transferred to the bank is $10 \mathrm{~A}$. 


\section{Experimental Results}

To verify the behavior of the CMS embedded with the experimental prototype of the DC- $\mu \mathrm{G}$, each of the PVEs was configured with the following parameters: $V_{m p p}=120 \mathrm{~V}, V_{o c}=130 \mathrm{~V}, I_{m p p}=2 \mathrm{~A}$ and $\mathrm{I}_{\mathrm{sc}}=3 \mathrm{~A}$. During the experimental tests, this configuration was used, although the PVEs can operate under uncertainties, it was not the objective of this investigation.

\subsection{PVEs' Ignition}

Before activating the CMS, the PVEs are switched on, the DC bus has a resistive load of $116 \mathrm{~W}$ and the $0.23 \mathrm{~F}$ supercapacitor bank, the DC-DC and DC-AC bidirectional converters are disabled and the DC-DC boost converter behaves like a short circuit by directly connecting the PVEs with the resistive load and the supercapacitor bank. Figure 15 shows the response of the DC bus during the activating of the PVEs. The DC bus takes $6.4 \mathrm{~s}$ to reach a voltage of $131 \mathrm{~V}$, this is due to the time it takes for the supercapacitor bank to absorb the PVEs energy.

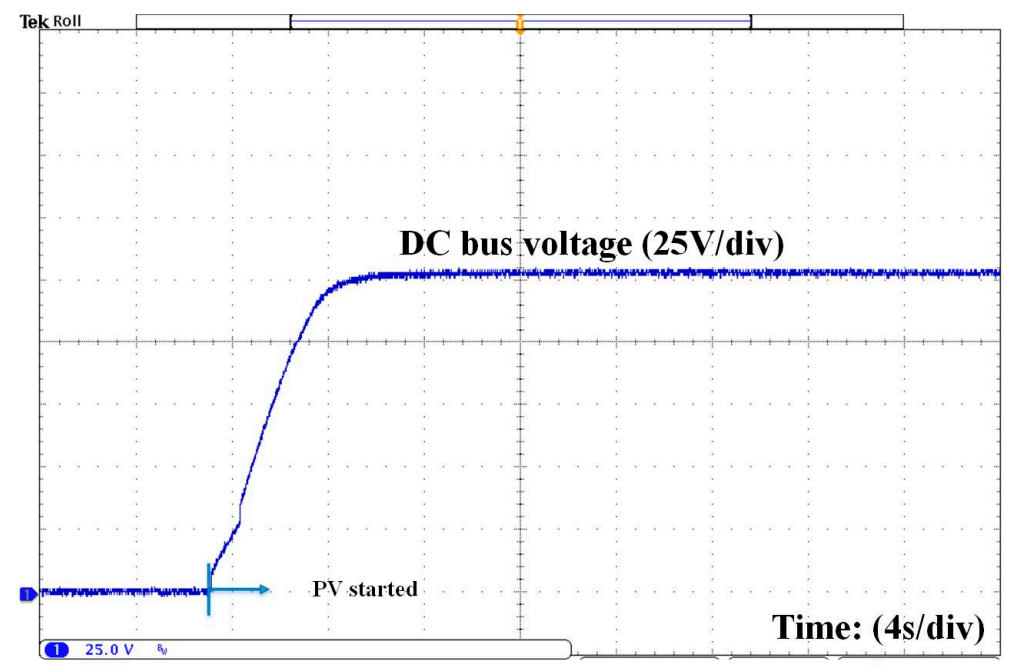

Figure 15. Bus behavior on the two photovoltaic emulators (PVEs) ignition.

\subsection{PVEs in Voltage Control Mode, MG and BB Disabled}

Once the DC bus stabilizes, the CMS is activated and the first operating condition is START, the MG and the BB remain disabled, while the PVEs converters work in VC mode. Figure 16 shows the response of the DC bus when activating the CMS, the VC needs $20 \mathrm{~s}$ to stabilize at the desired voltage level (190 V).

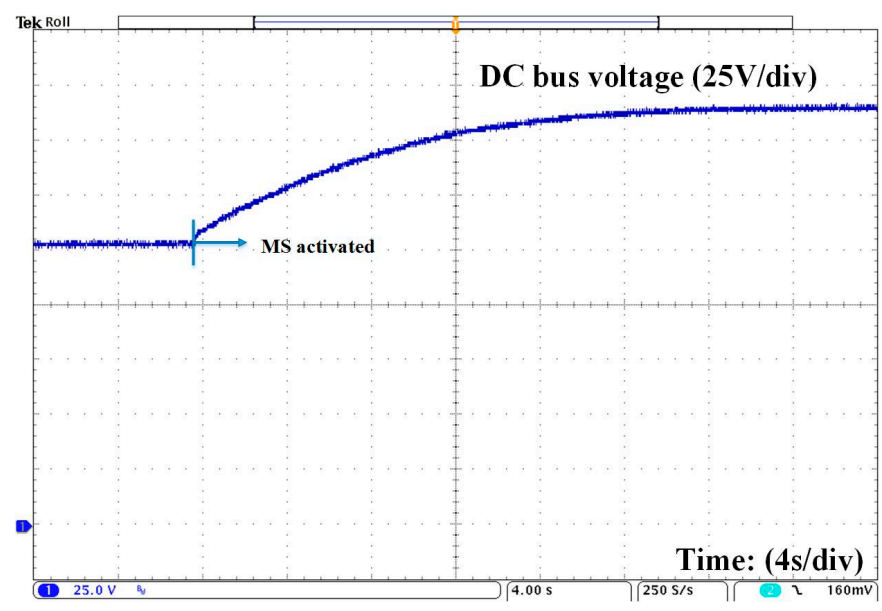

Figure 16. Bus behavior when the control and management system (CMS) is switched on. 
When the CMC works in the START condition, the system is able to keep the DC bus stable in case of load changes, the PVEs are responsible for supplying the energy demanded by the loads while the DC-DC boost converters operate in mode VC. Figure 17 shows the behavior when connecting a $115 \mathrm{~W}$ LED-type electronic lighting load, while Figure 18 shows the behavior when disconnecting the load. When the load is connected or disconnected, a drop and an overshoot of $1.5 \mathrm{~V}(0.78 \%)$ is generated regarding the established voltage level of $190 \mathrm{~V}$, the response has a transition time of $10 \mathrm{~s}$.

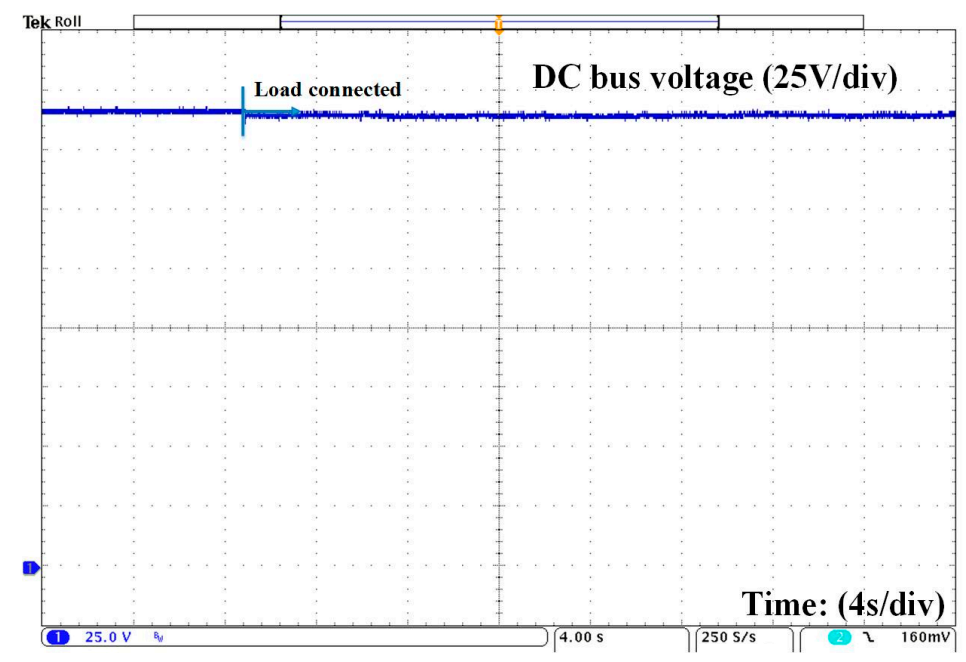

Figure 17. LED-type lamp connection.

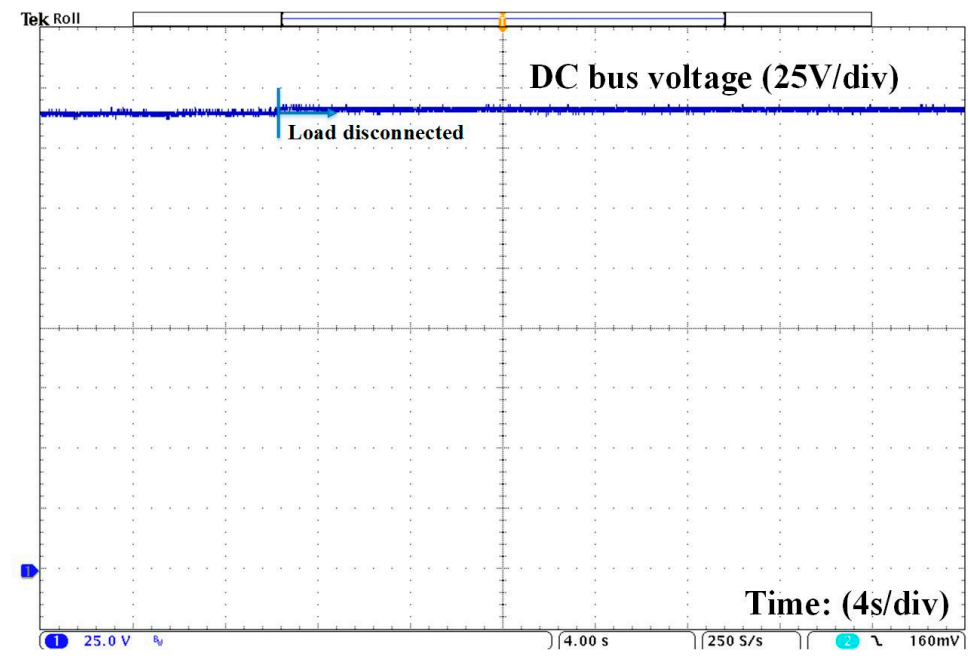

Figure 18. Disconnection of LED-type lamp.

A $300 \mathrm{~W}$ fluorescent luminaire was used in the experimental tests, Figure 19 illustrates the behavior of the DC bus when connecting the load, while Figure 20 shows the behavior when disconnecting it. When the load is connected, the bus has a voltage drop of $1.5 \mathrm{~V}(0.78 \%)$, while the load is disconnected there is an excess of $4.25 \mathrm{~V}(2.2 \%)$, both responses with a stabilization time of $4 \mathrm{~s}$. 


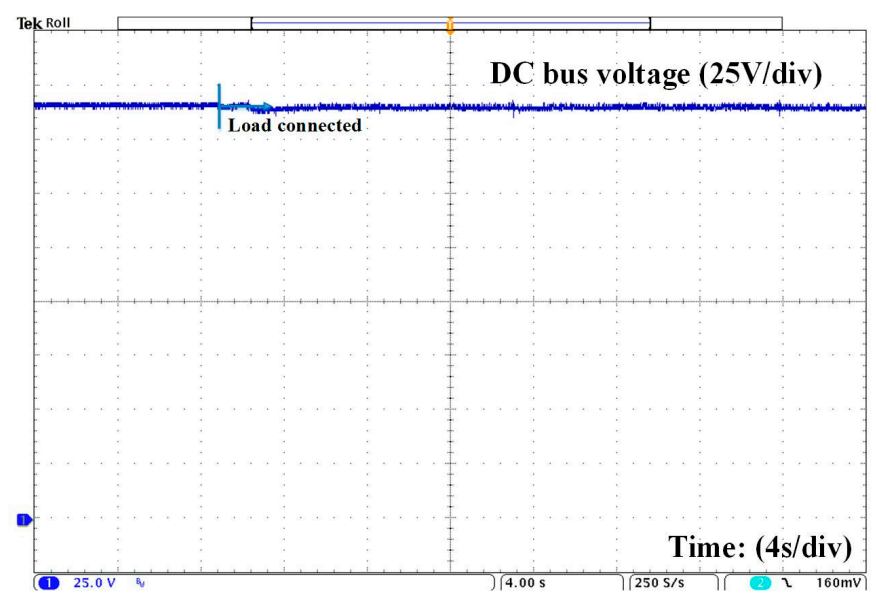

Figure 19. Connection of $300 \mathrm{~W}$ fluorescent lamps.

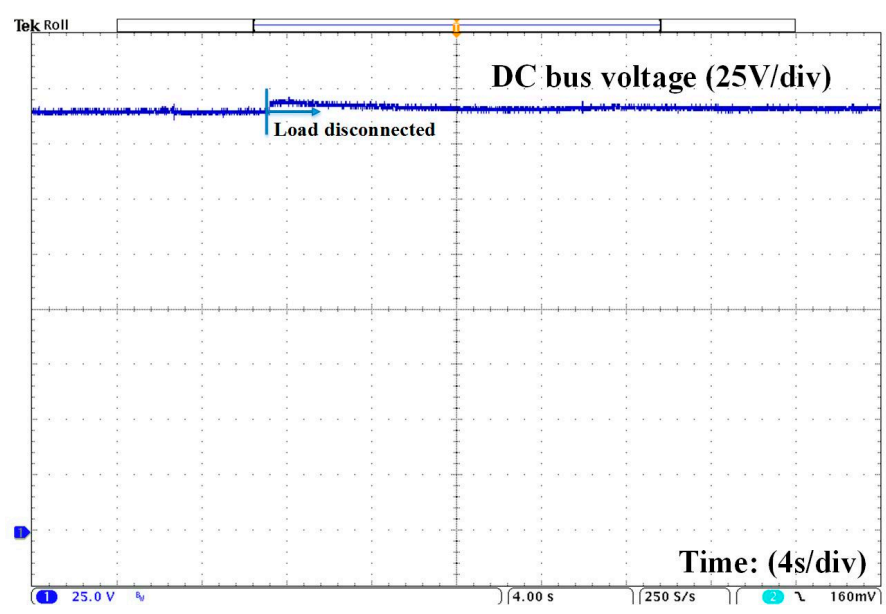

Figure 20. Disconnection of $300 \mathrm{~W}$ fluorescent lamps.

To verify the behavior of the GMS in the limit of the START state a fluorescent load of $400 \mathrm{~W}$ was used. When connecting this load, the energy generated by the PVEs is equal to the energy demanded by the loads, in Figures 21 and 22 the bus behavior, when connecting and disconnecting the load, is presented. When the load is connected, the bus has a voltage drop of $3 \mathrm{~V}(1.57 \%)$ when disconnecting, it has an overshoot of $7.5 \mathrm{~V}(3.94 \%)$, in both cases there is a stabilization time of $10 \mathrm{~s}$.

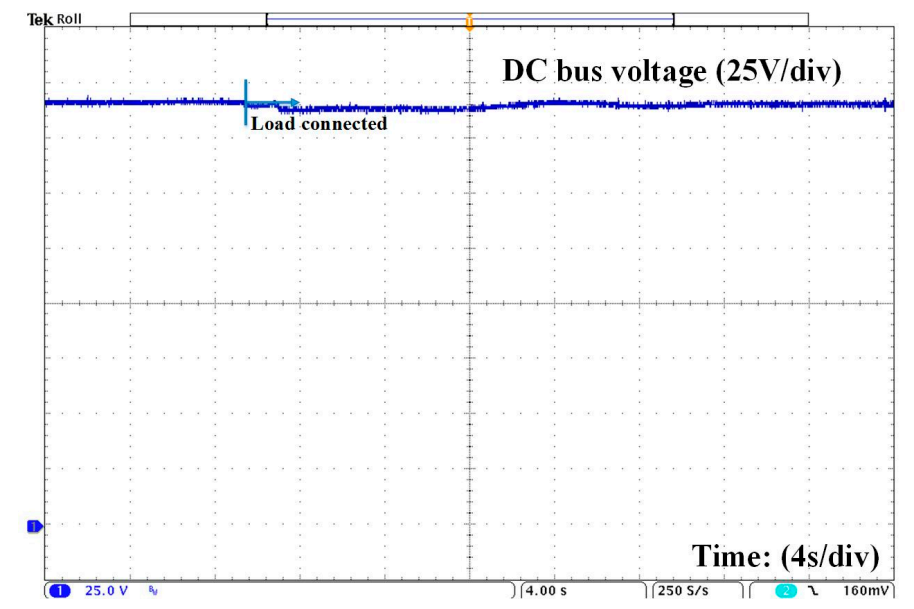

Figure 21. Connection of $400 \mathrm{~W}$ fluorescent lamps. 


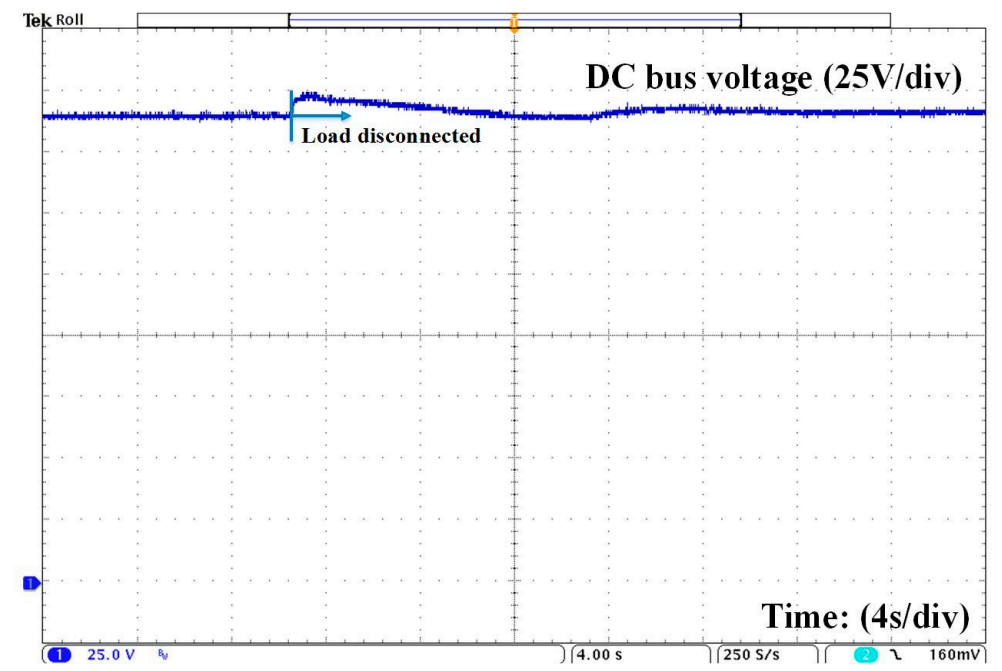

Figure 22. Disconnection of $400 \mathrm{~W}$ fluorescent lamps.

\subsection{DC-AC Converter Working as Rectifier, PVE's and BB Disabled}

When PVEs are not available to generate power, the GMC has the priority of transferring power from the MG to the DC bus while keeping the BB disabled. The GMC enables the DC-AC converter to work as a rectifier with the control system illustrated in Figure 14. Figure 23 shows the behavior of the bus when enabling the converter, at this moment the supercapacitor bank absorbs energy from the MG and stabilizes at a voltage level of $144 \mathrm{~V}$ in a time of $12 \mathrm{~s}$. Next, the GMC activates the rectifier controller by stabilizing the bus at the desired voltage level of $190 \mathrm{~V}$ (See Figure 24). The DC bus has a stabilization time of $12 \mathrm{~s}$.

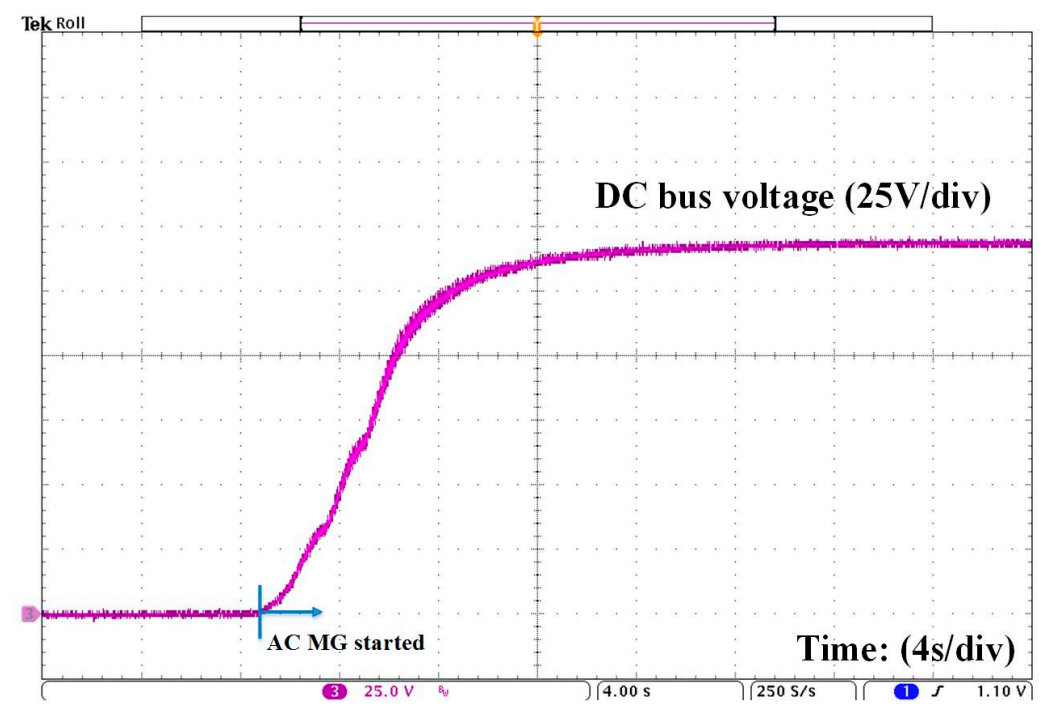

Figure 23. Connection to the main grid (MG). 


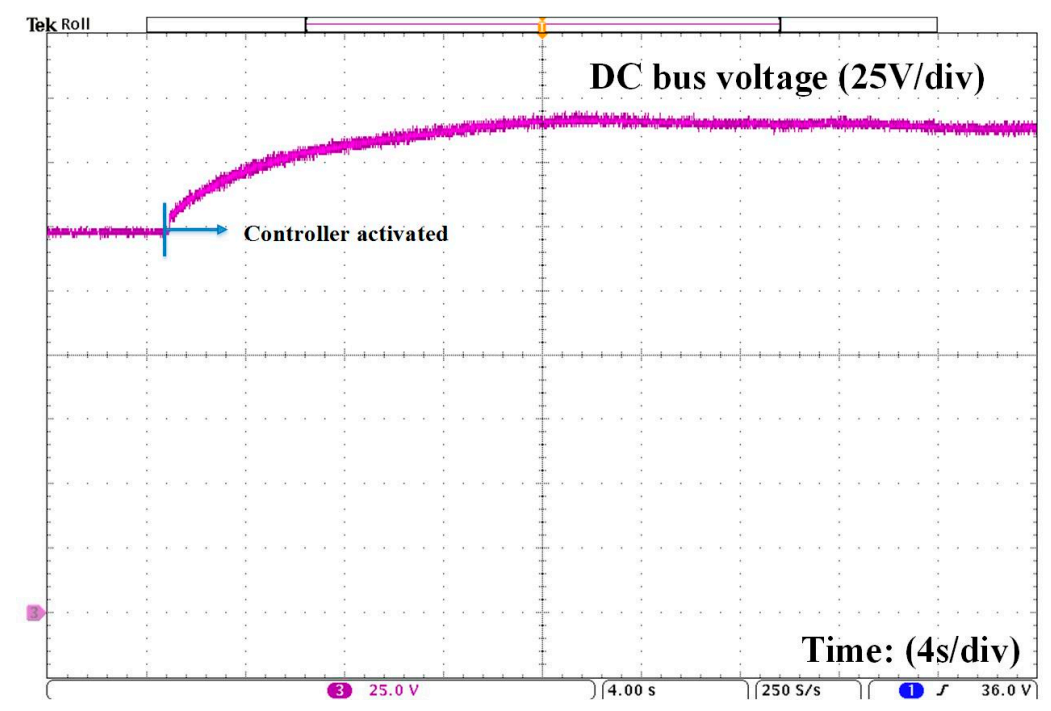

Figure 24. Ignition of the control for the rectifier.

For this case, the same loads were used as in the previous case, presenting the behavior of the DC bus before the connection (Con) and disconnection (Discon) of these loads, in Figures 25 and 26 a $115 \mathrm{~W}$ LED luminaire is used, in Figures 27 and 28 a fluorescent luminaire (FL) of $300 \mathrm{~W}$, finally in Figures 29 and 30 a FL of 400 W. Table 8 shows the voltage drops (D), the overshoots (O) and the stabilization times before these disturbances. This table presents the behavior of the DC bus under the following conditions: (1) MG supplying power to the loads, (2) PVEs supplying power to the loads, (3) MG supplying power to the loads and the BB and (4) PVEs supplying power to the loads and the BB.

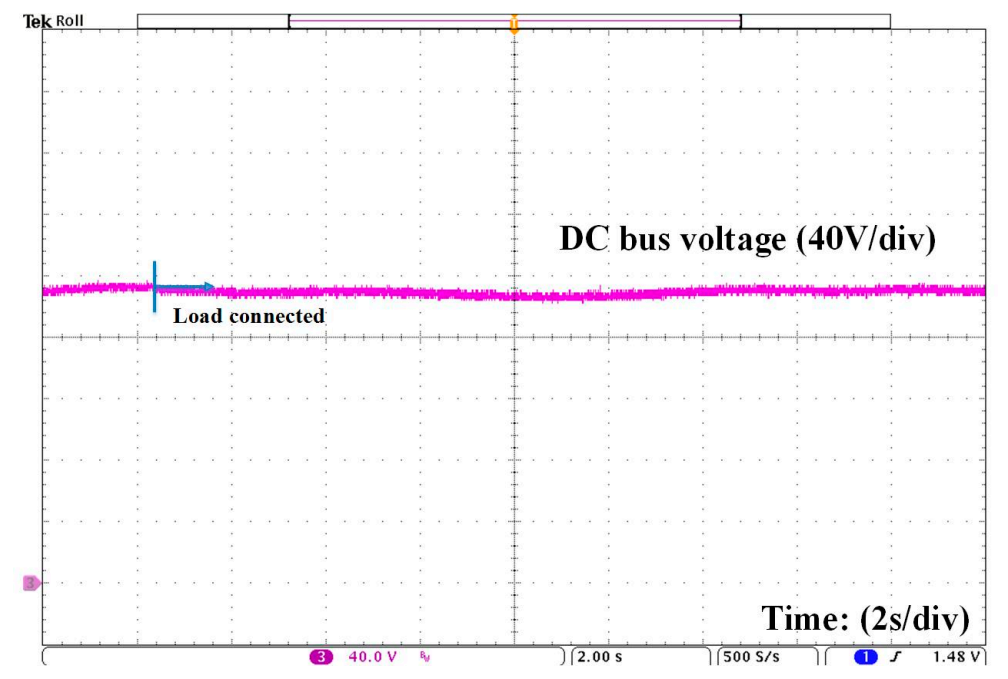

Figure 25. Connection of 115 W LED lamp. 


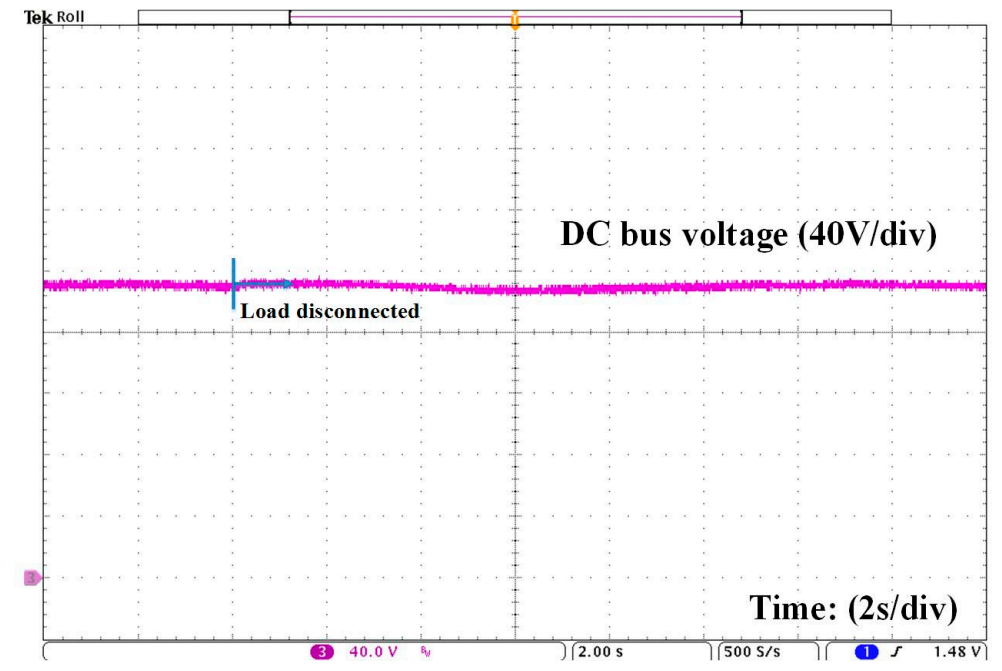

Figure 26. Disconnection of 115 W LED lamp.

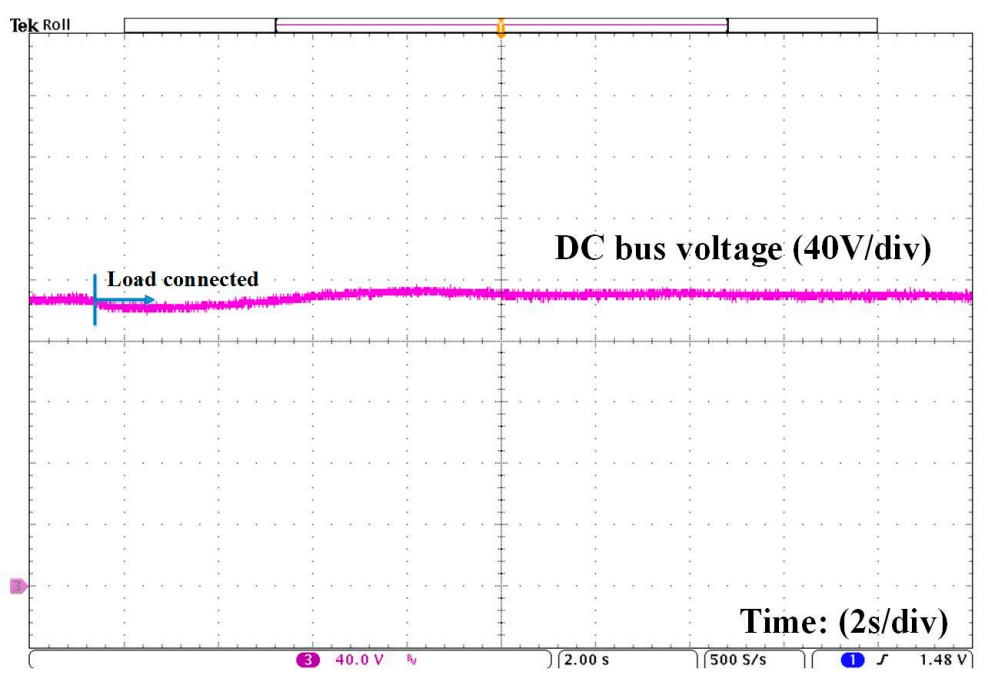

Figure 27. Connection of $300 \mathrm{~W}$ fluorescent lamps.

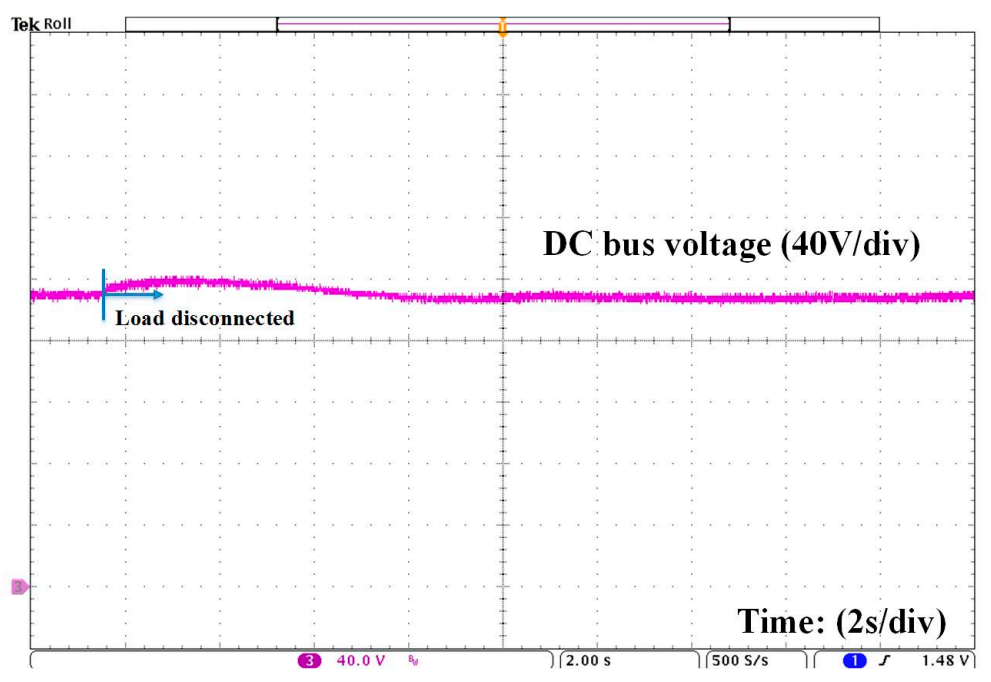

Figure 28. Disconnection of $300 \mathrm{~W}$ fluorescent lamps. 


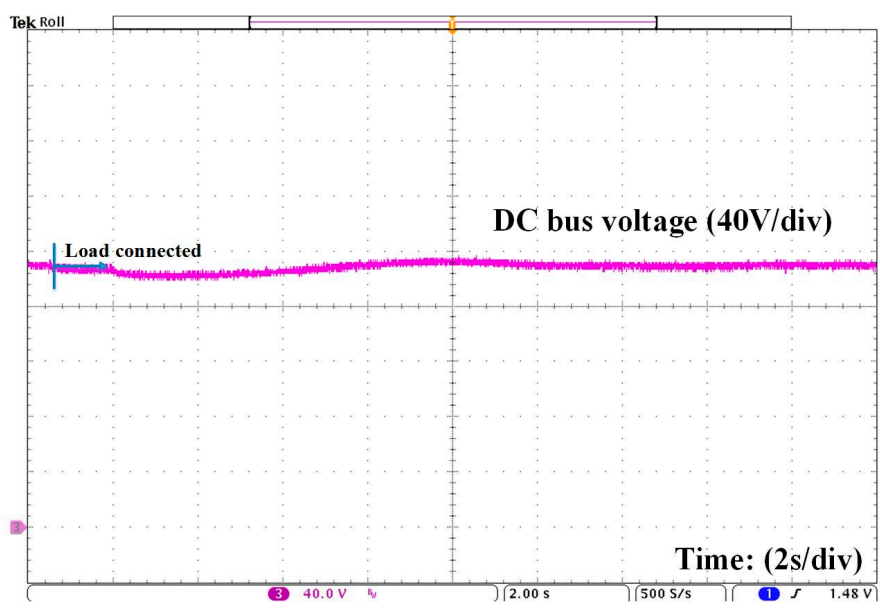

Figure 29. Connection of $400 \mathrm{~W}$ fluorescent lamps.

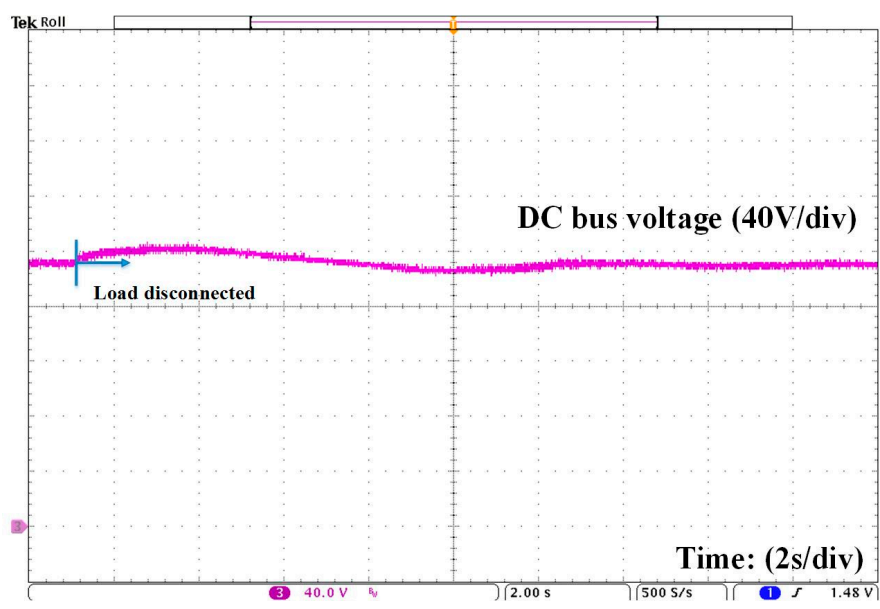

Figure 30. Disconnection of $400 \mathrm{~W}$ fluorescent lamps.

Table 8. Response of the DC- $\mu \mathrm{G}$ to the connection and disconnection of loads and sources.

\begin{tabular}{|c|c|c|c|c|c|c|}
\hline \multicolumn{7}{|c|}{ MG Supplying Power to the Loads } \\
\hline \multirow{2}{*}{ Response } & \multicolumn{6}{|c|}{ Loads } \\
\hline & Con LED & Discon LED & Con FL $300 \mathrm{~W}$ & Discon FL $300 \mathrm{~W}$ & Con FL $400 \mathrm{~W}$ & Discon FL $400 \mathrm{~W}$ \\
\hline Disturbance & $\begin{array}{c}2.4 \mathrm{~V}(\mathrm{D}) \\
(1.26 \%)\end{array}$ & $\begin{array}{l}2 \mathrm{~V}(\mathrm{O}) \\
(1.05 \%)\end{array}$ & $\begin{array}{l}4 \mathrm{~V}(\mathrm{D}) \\
(2.1 \%)\end{array}$ & $\begin{array}{l}8 \mathrm{~V}(\mathrm{O}) \\
(4.2 \%)\end{array}$ & $\begin{array}{l}8 \mathrm{~V}(\mathrm{D}) \\
(4.2 \%)\end{array}$ & $\begin{array}{l}8 \mathrm{~V}(\mathrm{O}) \\
(4.2 \%)\end{array}$ \\
\hline Timing & $4 \mathrm{~s}$ & $4 \mathrm{~s}$ & $6 \mathrm{~s}$ & $6 \mathrm{~s}$ & $6 s$ & $6 \mathrm{~s}$ \\
\hline \multicolumn{7}{|c|}{ PVEs Supplying Power to the Loads } \\
\hline \multirow{2}{*}{ Response } & \multicolumn{6}{|c|}{ Loads } \\
\hline & Con LED & Discon LED & Con FL $300 \mathrm{~W}$ & Discon FL $300 \mathrm{~W}$ & Con FL $400 \mathrm{~W}$ & Discon FL $400 \mathrm{~W}$ \\
\hline Disturbance & $\begin{array}{c}1.5 \mathrm{~V}(\mathrm{D}) \\
(0.78 \%)\end{array}$ & $\begin{array}{c}1.5 \mathrm{~V}(\mathrm{O}) \\
(0.78 \%)\end{array}$ & $\begin{array}{c}1.5 \mathrm{~V}(\mathrm{D}) \\
(0.78 \%)\end{array}$ & $\begin{array}{c}4.25 \mathrm{~V}(\mathrm{O}) \\
(2.2 \%)\end{array}$ & $\begin{array}{l}3 \mathrm{~V}(\mathrm{D}) \\
(1.57 \%)\end{array}$ & $\begin{array}{c}7.5 \mathrm{~V}(\mathrm{O}) \\
(3.94 \%)\end{array}$ \\
\hline Timing & $10 \mathrm{~s}$ & $10 \mathrm{~s}$ & $4 \mathrm{~s}$ & $4 \mathrm{~s}$ & $10 \mathrm{~s}$ & $10 \mathrm{~s}$ \\
\hline \multicolumn{7}{|c|}{ MG Supplying Power to the Loads and the BB } \\
\hline \multirow{2}{*}{ Response } & \multicolumn{6}{|c|}{ Operation } \\
\hline & \multicolumn{3}{|c|}{ Activation } & \multicolumn{3}{|c|}{ Deactivation } \\
\hline Disturbance & \multicolumn{3}{|c|}{$1.65 \mathrm{~V}(\mathrm{D})(0.86 \%)$} & \multicolumn{3}{|c|}{$2.5 \mathrm{~V}(\mathrm{O})(1.31 \%)$} \\
\hline Timing & \multicolumn{3}{|c|}{$10 \mathrm{~s}$} & \multicolumn{3}{|c|}{$4 \mathrm{~s}$} \\
\hline \multicolumn{7}{|c|}{ PVEs Supplying Power to the Loads and the BB } \\
\hline \multirow{2}{*}{ Response } & \multicolumn{6}{|c|}{ Operation } \\
\hline & \multicolumn{3}{|c|}{ Activation } & \multicolumn{3}{|c|}{ Deactivation } \\
\hline Disturbance & \multicolumn{3}{|c|}{$8.75 \mathrm{~V}(\mathrm{D})(4.6 \%)$} & \multicolumn{3}{|c|}{$8.75 \mathrm{~V}(\mathrm{O})(4.6 \%)$} \\
\hline Timing & \multicolumn{3}{|c|}{$6 \mathrm{~s}$} & \multicolumn{3}{|c|}{$6 \mathrm{~s}$} \\
\hline
\end{tabular}




\subsection{Disabled PVEs, MG Supplying Energy to the Loads and the BB}

When the MG is supplying power to the loads connected to the DC bus and the power is less than $1 \mathrm{~kW}$, the remaining energy is transferred to the $\mathrm{BB}\left(\mathrm{P}_{\mathrm{BB}}=1 \mathrm{~kW}-\mathrm{P}_{\mathrm{LOADS}}\right)$. The control of the energy that is transferred to the $\mathrm{BB}$ is determined by the current that is injected into the $\mathrm{BB}$ (the setpoint of this power is determined from the $\mathrm{P}_{\mathrm{BB}}$ ), in this operation mode the bidirectional DC-DC converter works as a buck.

Figure 31 shows the behavior of the $\mathrm{DC}$ bus and the power that is injected into the $\mathrm{BB}$ when activating the $\mathrm{DC}-\mathrm{DC}$ bidirectional converter as a buck. When activating the energy transfer to the $\mathrm{BB}$, the $\mathrm{DC}$ bus has a voltage drop of $1.65 \mathrm{~V}(0.86 \%)$, while the power injected into the $\mathrm{BB}$ takes the desired level of $3 \mathrm{~A}$, this transition has a stabilization time of $10 \mathrm{~s}$. When energy is being transferred to the $\mathrm{BB}$ and it is charged at $80 \%$, the power injected into the BB is canceled. Figure 32 shows the behavior of the current and the DC bus at the time of changing the operating mode. At the time of the transition, the DC bus has a $2.5 \mathrm{~V}(1.31 \%)$ overshoot with a stabilization time of $4 \mathrm{~s}$.

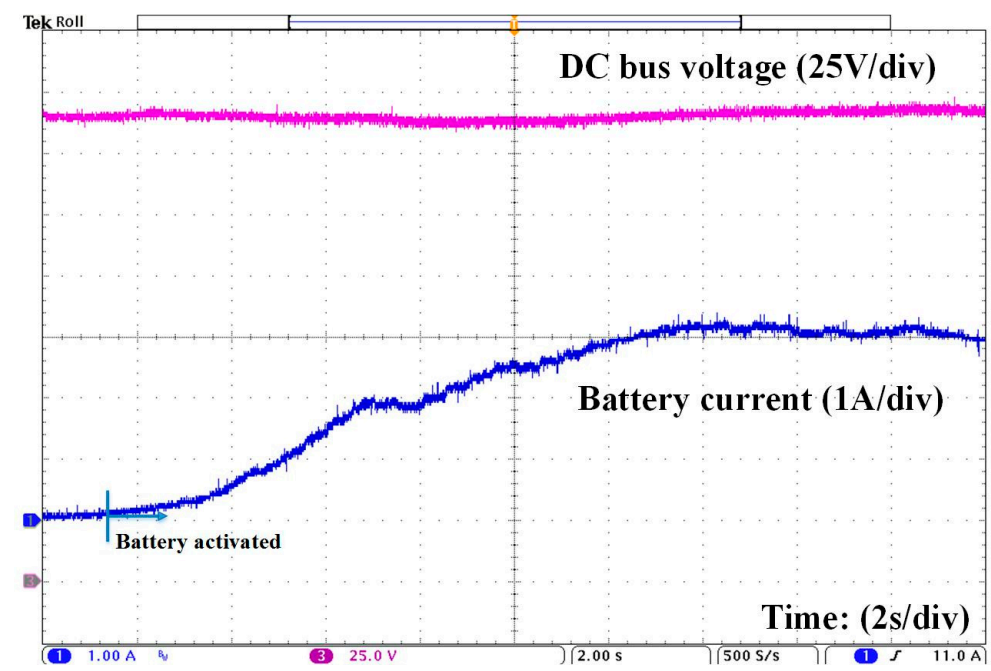

Figure 31. Start of the power supply to the battery bank (BB).

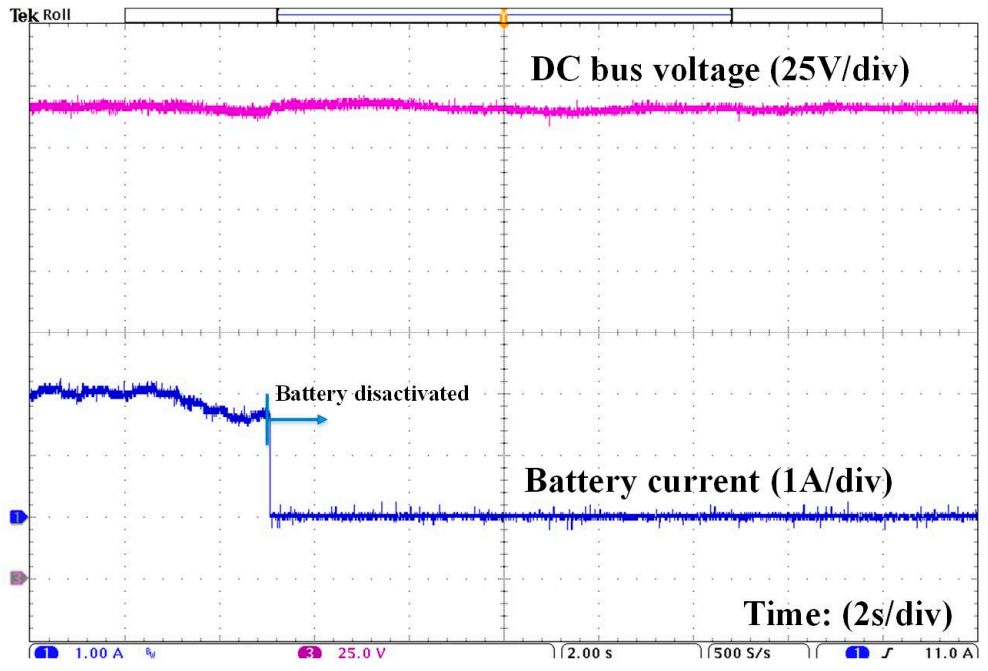

Figure 32. End of the power supply to the BB.

\subsection{PVEs Supplying Energy to the Loads and to BB and Disabled MG}

Another way to transfer energy to the $\mathrm{BB}$ is to use excess energy from the PVEs. In this state, the energy transferred to the $\mathrm{BB}$ is determined by $\mathrm{P}_{\mathrm{BB}}=\mathrm{P}_{\mathrm{PVEs}}-\mathrm{P}_{\text {LOADS }}$. If the control of the DC-DC 
converters of the PVEs is in VC mode and the extracted power is less than $80 \%$ of the maximum power, the GMC modifies its operating state, changing the VC mode to the MPPT mode in the converters of the PVEs and activating the control for the bidirectional DC-DC converter of the BB in buck mode.

Figure 33 illustrates the behavior of the DC bus and the current (power) that is injected into the BB. When changing state, the bus suffers a voltage drop of $8.75 \mathrm{~V}(4.6 \%)$ with a stabilization time of $6 \mathrm{~s}$, while the current takes its maximum value in $3 \mathrm{~s}$. The current has constant variations because the control algorithm for the MPPT is responsible for disturbing the energy generated by the PVEs, which affects the injected current to the BB and the DC bus. Figure 34 shows the behavior of the same signals when the BB stops transferring energy.

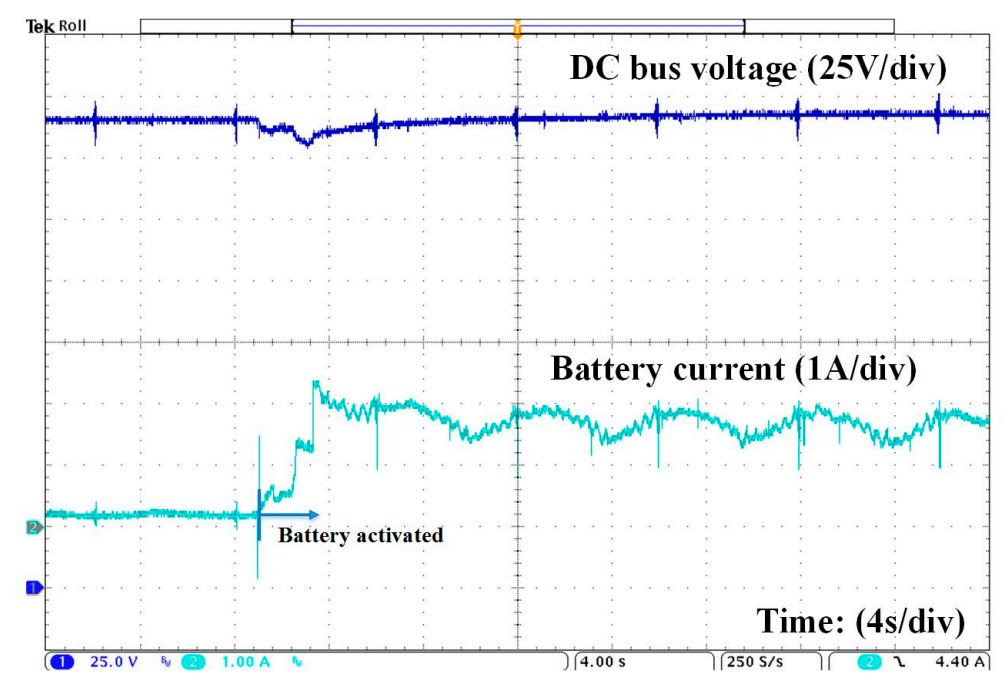

Figure 33. Start of the power supply to the BB.

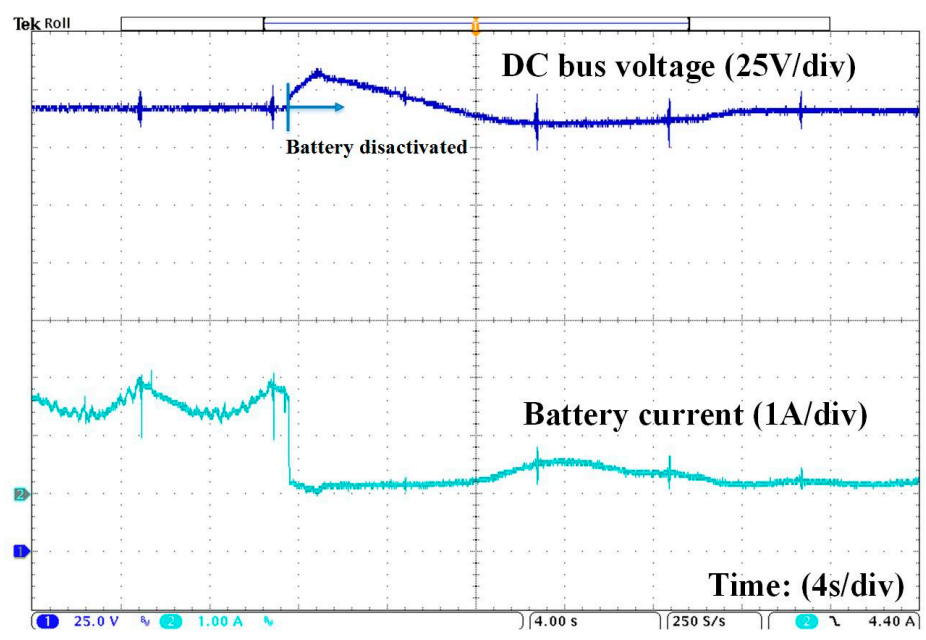

Figure 34. End of the power supply to the BB.

To recognize the dynamic response of the $\mathrm{BB}$ in the charging process, the bidirectional converter was used in buck mode, this converter takes the electrical energy generated by the PVEs and transfers it to the BB. When the BB is fully discharged, the constant current charge is carried out maintaining a current (power) level of $8.8 \mathrm{~A}$ (because the maximum capacity of the bidirectional DC-DC converter is $1 \mathrm{~kW})$, as the time passes the BB voltage tends to increase up to a voltage level of $135 \mathrm{~V}$, at this moment the control changes to constant voltage mode, decreasing the current that is transferred to the BB. The $\mathrm{BB}$ is considered to be fully charged when the current supplied is $500 \mathrm{~mA}$. Figure 35 illustrates the behavior of the $\mathrm{BB}$ voltage while charging in constant power mode and voltage, the charge in constant 
power mode has a duration of $8 \mathrm{~h}$, while the charge in constant voltage mode was $8.5 \mathrm{~h}$. The behavior of the current in both modes is illustrated in Figure 36.

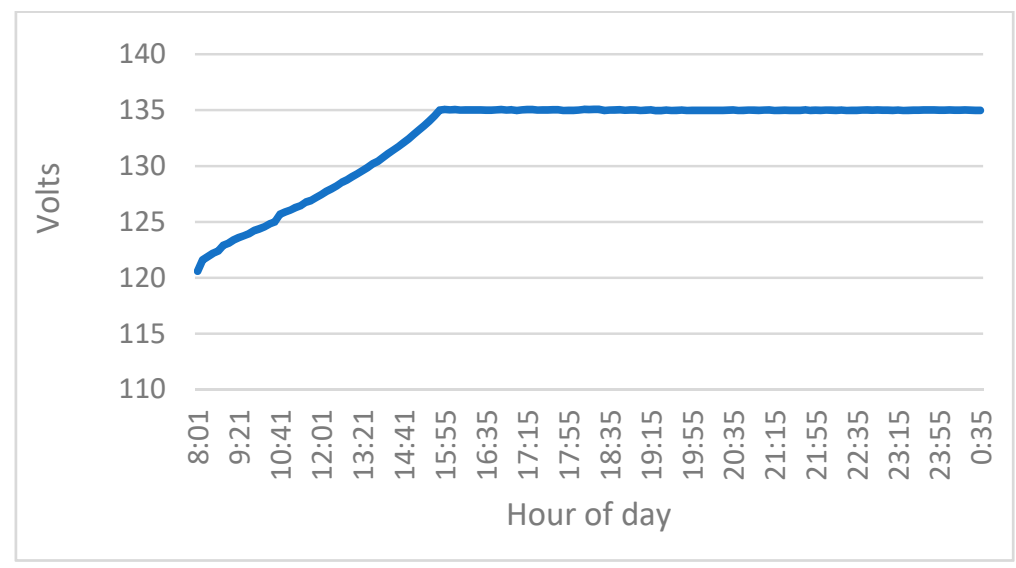

Figure 35. BB voltage in charging mode.

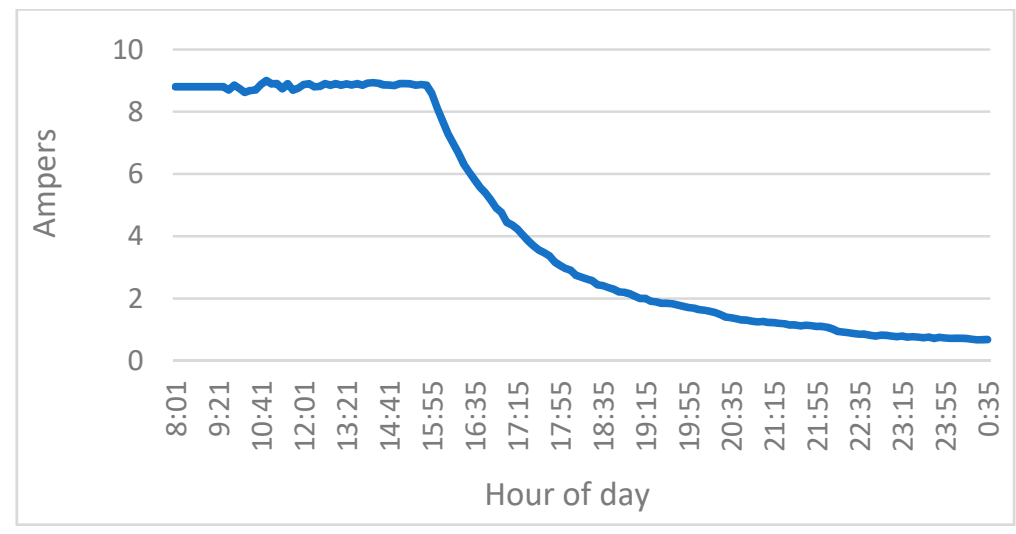

Figure 36. BB current in charging mode.

\subsection{BB Supplying Energy to the Loads, Disabled PVEs and MG}

After conducting experimental tests of the BB's charge, obtaining energy from the MG and the PVEs, the behavior of the BB's charging and discharging process is presented. For these tests, a load was connected to the DC bus that requires a constant power of $1 \mathrm{~kW}$ (maximum power of the $\mu \mathrm{G}$ ), while the bidirectional converter works in boost mode keeping the voltage of the DC bus at $190 \mathrm{~V}$. The behavior of the BB voltage with an initial voltage of $121.2 \mathrm{~V}$ is shown in Figure 37; as time passes, the BB voltage decreases and this generates an increase in the current delivered by the BB (See Figure 38), this due to a constant power of $1 \mathrm{~kW}$ being demanded for the load connected to the bus. Figure 38 presents the behavior of the BB current at the discharge. The discharge was carried out until the BB voltage dropped to a level of $100 \mathrm{~V}$, so as not to damage the $\mathrm{BB}$ following the specifications given by the manufacturer. Under these conditions, the DC-DC converter was able to maintain the voltage level of the DC bus at a level of $190 \mathrm{~V}$ while supplying power at a $1 \mathrm{~kW}$ load for approximately $10 \mathrm{~h}$ until the $\mathrm{BB}$ was discharged. 


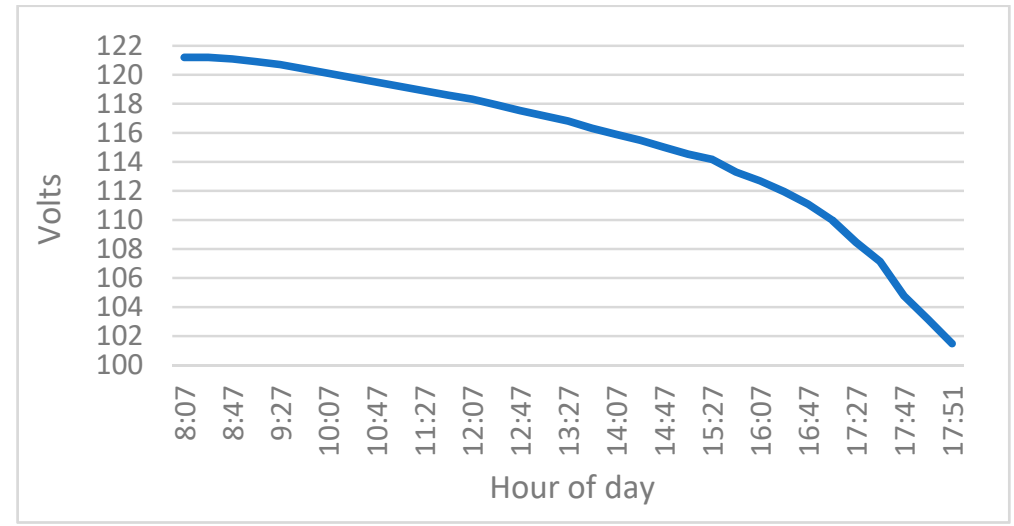

Figure 37. BB voltage in discharge mode.

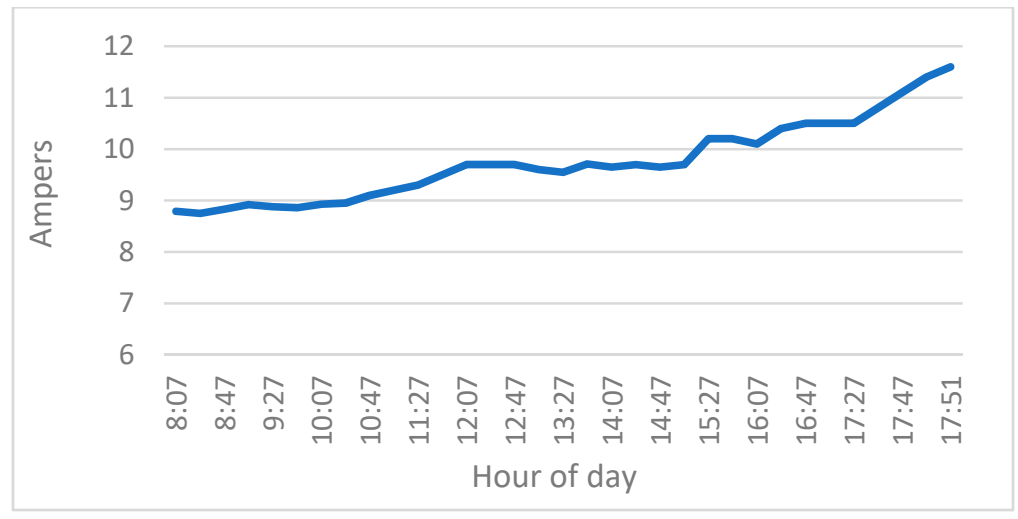

Figure 38. BB current in discharge mode.

\subsection{PVEs Supplying Power to the Loads and the MG, Disabled BB}

In this test, the interconnection of the DC- $\mu \mathrm{G}$ with the MG is generated. In this condition the PVEs operate with the control algorithm for the MPPT and the DC-AC converter is enabled as an inverter transferring energy from the PVEs to the MG. In this way, the remaining energy between the energy generated by the PVEs and the energy consumed by the loads connected to the DC bus $\left(\mathrm{P}_{\mathrm{MG}}=\mathrm{P}_{\mathrm{PVES}}-\mathrm{P}_{\mathrm{LOADS}}\right)$ is transferred to the MG. During the interconnection with the MG the voltage level of the DC bus suffers a drop of $2.2 \%$ with a duration of the transitory response of $6 \mathrm{~s}$. Figure 39 shows the AC output voltage-current oscillogram of the inverter interconnected with the MG supplying $320 \mathrm{~W}$. This image illustrates the AC voltage and power signals when performing the energy transfer; In addition, the instantaneous power being supplied to the AC MG and the power factor are displayed.

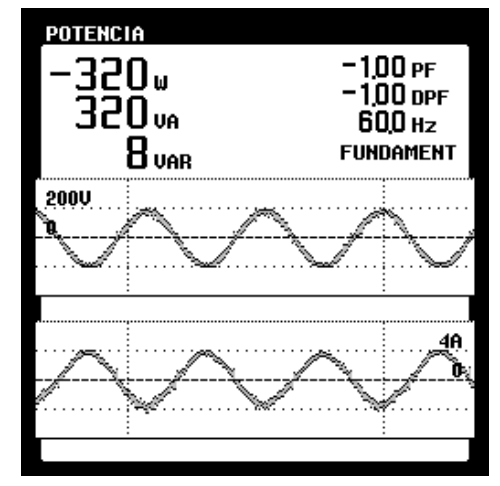

Figure 39. Output voltage-current oscillograms of the interconnected inverter with the MG. 


\section{Conclusions}

This study shows the design and implementation of a management and control system applied to an experimental prototype of a DC- $\mu \mathrm{G}$ for a maximum power of $1 \mathrm{~kW}$ with a DC bus with a voltage level $190 \mathrm{~V}$, which can operate isolated or interconnected with the MG. The proposed DC- $\mu \mathrm{G}$ is made up of two photovoltaic systems, a complete bridge inverter, a BB and electronic loads (LED-type, fluorescent and computer equipment). For the administration and control of energy in the $\mathrm{DC}-\mu \mathrm{G}$, an EMS was implemented on the NI myRIO-1900 platform using the LabVIEW virtual programming software for the design of the EMS.

In the experimental results, the operation of the $\mathrm{DC}-\mu \mathrm{G}$ is presented under principle operating conditions, all of them with the objective of evaluating the response of the DC bus to disturbances caused by the connection and disconnection of energy sources and real electronic loads. Throughout the different tests carried out, it was observed that the voltage bus of the proposed DC- $\mu \mathrm{G}$ remains within the operating range established in the design, and in each case the transitory response time ranged between 4 and $20 \mathrm{~s}$. These periods are suitable for the design of the DC- $\mu \mathrm{G}$ because the voltage peaks and drops in the DC bus do not exceed $5 \%$ of the nominal value of the bus, this period is defined by the capacitance that the bus presents, that increased with the use of the bank of supercapacitors. This can result in the proposed bus voltage of the $D C-\mu \mathrm{G}$ being able to achieve short-term stability after being exposed to different disturbances. In addition, in the experiments performed, no inconvenience was observed in the operation of the power converters, so it is suggested that it is possible to extrapolate the design of the proposed DC- $\mu \mathrm{G}$ to a higher power.

Our proposal for administration and energy control of a DC- $\mu \mathrm{G}$ based on a state machine that presents response times similar to those shown in [30]. The authors obtained times between 4 and $37 \mathrm{~s}$ in 15 different operation modes using a supervisory control based on a state machine to satisfy the energy demand of an $\mathrm{AC} / \mathrm{DC} \mu \mathrm{G}$ and a $\mathrm{FC}$ to maintain the $\mathrm{S}^{\circ} \mathrm{C}$ of a $\mathrm{BB}$. The effectiveness of the proposed was evaluated through extensive numeric simulations.

During the experiments that were carried out in this research, problems related to system instability caused by the dynamic interaction of the converters and/or impedances were not observed. For the design of the PECs, design techniques such as the one reported by [31] were used, taking into account whether the PEC commutes at a frequency at least ten times greater than the dynamics of the output voltage (or current), the switching noise is not mixed. The control technique used in parallel converters, in addition to the ratio of the impedances of the input/output sources contributed to the dynamics [32]. However, for future studies, a stability study, under conditions of higher power and a greater number of distributed generations (DGs) and loads, is necessary to ensure stability in certain interaction scenarios in the MG. If the noise is present in the complete system, a stability analysis can be done using the impedance of the source output filter and the input filter of the loads to find the loop with the lowest gain and evaluate it against criteria such as phase gain- phase margin or others [33-35].

Finally, for further study, the dimensioning of the components of the $D C-\mu G$ proposed in order to make it economically viable will be considered. The methodology proposed by [36] is viable for this purpose because it demonstrates the effectiveness of a sizing method based on genetic algorithms applied to EMS similar to that proposed in this article. From the point of view of power electronics, the increase in the number of DGs represents a greater number of switched power converters. Dynamics under voltage drop conditions could present a problem in the stability of the DC bus.

Author Contributions: Investigation, A.P.-M.; Methodology, F.P.-P. and A.V.-L.; Project Administration, J.M.-N.; Validation, A.J.-G. All authors have read and agree to the published version of the manuscript.

Funding: This research received no external funding.

Conflicts of Interest: The authors declare no conflict of interest. 


\section{References}

1. Yu, Y.; Wada, K. Simulation Study of Power Management for a Highly Reliable Distribution System using a Triple Active Bridge Converter in a DC Microgrid. Energies 2018, 11, 3178. [CrossRef]

2. Wang, H.; Huang, J. Joint investment and operation of microgrid. IEEE Trans. Smart Grid 2015, 8, 833-845. [CrossRef]

3. Wang, H.; Huang, J. Incentivizing energy trading for interconnected microgrids. IEEE Trans. Smart Grid 2016, 9, 2647-2657. [CrossRef]

4. Anvari-Moghaddam, A.; Guerrero, J.M.; Vasquez, J.C.; Monsef, H.; Rahimi-Kian, A. Efficient energy management for a grid-tied residential microgrid. IET Gener. Transm. Distrib. 2017, 11, 2752-2761. [CrossRef]

5. García Elvira, D.; Valderrama Blaví, H.; Cid Pastor, À.; Martínez Salamero, L. Efficiency optimization of a variable bus voltage DC microgrid. Energies 2018, 11, 3090. [CrossRef]

6. Dragičević, T.; Lu, X.; Vasquez, J.C.; Guerrero, J.M. DC microgrids-Part I: A review of control strategies and stabilization techniques. IEEE Trans. Power Electron. 2015, 31, 4876-4891. [CrossRef]

7. Arunkumar, G.; Elangovan, D.; Sanjeevikumar, P.; Nielsen, J.B.H.; Leonowicz, Z.; Joseph, P.K. DC Grid for Domestic Electrification. Energies 2019, 12, 2157. [CrossRef]

8. Zhao, Z.; Zhang, J.; He, Y.; Zhang, Y. Island DC Microgrid Hierarchical Coordinated Multi-Mode Control Strategy. Energies 2019, 12, 3012. [CrossRef]

9. Zhang, Y.; Li, Y.W. Energy management strategy for supercapacitor in droop-controlled DC microgrid using virtual impedance. IEEE Trans. Power Electron. 2016, 32, 2704-2716. [CrossRef]

10. Zhao, X.; Li, Y.W.; Tian, H.; Wu, X. Energy management strategy of multiple supercapacitors in a DC microgrid using adaptive virtual impedance. IEEE J. Emerg. Sel. Top. Power Electron. 2016, 4, 1174-1185. [CrossRef]

11. Beykverdi, M.; Jalilvand, A.; Ehsan, M. Cooperative energy management of hybrid DC renewable grid using decentralized control strategies. Energies 2016, 9, 859. [CrossRef]

12. Chen, M.; Ma, S.; Wan, H.; Wu, J.; Jiang, Y. Distributed Control Strategy for DC Microgrids of Photovoltaic Energy Storage Systems in Off-Grid Operation. Energies 2018, 11, 2637. [CrossRef]

13. Al-Sakkaf, S.; Kassas, M.; Khalid, M.; Abido, M.A. An energy management system for residential autonomous DC microgrid using optimized fuzzy logic controller considering economic dispatch. Energies 2019, 12, 1457. [CrossRef]

14. Zhang, L.; Chen, K.; Chi, S.; Lyu, L.; Cai, G. The Hierarchical Control Algorithm for DC Microgrid Based on the Improved Droop Control of Fuzzy Logic. Energies 2019, 12, 2995. [CrossRef]

15. Zhang, L.; Chen, K.; Lyu, L.; Cai, G. Research on the Operation Control Strategy of a Low-Voltage Direct Current Microgrid Based on a Disturbance Observer and Neural Network Adaptive Control Algorithm. Energies 2019, 12, 1162. [CrossRef]

16. Wu, H.; Locment, F.; Sechilariu, M. Experimental Implementation of a Flexible PV Power Control Mechanism in a DC Microgrid. Energies 2019, 12, 1233. [CrossRef]

17. Han, Y.; Chen, W.; Li, Q. Energy management strategy based on multiple operating states for a photovoltaic/fuel cell/energy storage DC microgrid. Energies 2017, 10, 136. [CrossRef]

18. Salas-Puente, R.; Marzal, S.; González-Medina, R.; Figueres, E.; Garcera, G. Experimental study of a centralized control strategy of a DC microgrid working in grid connected mode. Energies 2017, 10, 1627. [CrossRef]

19. Chen, Y.K.; Wu, Y.C.; Song, C.C.; Chen, Y.S. Design and implementation of energy management system with fuzzy control for DC microgrid systems. IEEE Trans. Power Electron. 2012, 28, 1563-1570. [CrossRef]

20. Behera, R.K.; Parida, S.K. DC microgrid management using power electronics converters. In Proceedings of the IEEE Eighteenth National Power Systems Conference, Guwahati, India, 18-20 December 2014; pp. 1-6.

21. Zadeh, M.K.; Saublet, L.M.; Gavagsaz-Ghoachani, R.; Nahid-Mobarakeh, B.; Pierfederici, S.; Molinas, M. Energy management and stabilization of a hybrid DC microgrid for transportation applications. In Proceedings of the IEEE Applied Power Electronics Conference and Exposition, Long Beach, CA, USA, 20-24 March 2016; pp. 3397-3402.

22. Hosseinzadeh, M.; Rajaei Salmasi, F. Fault-Tolerant Supervisory Controller for a Hybrid AC/DC Micro-Grid. IEEE Trans. Smart Grid 2018, 9, 2809-2823. [CrossRef] 
23. Sedaghati, R.; Shakarami, M.R. A Novel Control Strategy and Power Management of Hybrid PV/FC/SC/Battery Renewable Power System-Based Grid-Connected Microgrid. Sustain. Cities Soc. 2018. [CrossRef]

24. Prasana, R.J.K.; Ramprasath, S.; Vijayasarathi, N. Design and analysis of hybrid DC-DC boost converter in continuous conduction mode. In Proceedings of the IEEE International Conference on Circuit, Power and Computing Technologies, Nagercoil, India, 18-19 March 2016; pp. 1-5.

25. Attanasio, R.; Gennaro, F.; Scuderi, G. A grid tie micro inverter with reactive power control capability. In Proceedings of the AEIT Annual Conference, Mondello, Italy, 3-5 October 2013; pp. 1-6.

26. Cao, J.; Schofield, N.; Emadi, A. Battery balancing methods: A comprehensive review. In Proceedings of the IEEE Vehicle Power and Propulsion Conference, Harbin, China, 3-5 September 2008; pp. 1-6.

27. Killi, M.; Samanta, S. Modified perturb and observe MPPT algorithm for drift avoidance in photovoltaic systems. IEEE Trans. Ind. Electron. 2015, 62, 5549-5559. [CrossRef]

28. Kwon, M.; Choi, S. Control scheme for autonomous and smooth mode switching of bidirectional DC-DC converters in a DC microgrid. IEEE Trans. Power Electron. 2017, 33, 7094-7104. [CrossRef]

29. Li, X.; Guo, L.; Zhang, S.; Wang, C.; Li, Y.W.; Chen, A.; Feng, Y. Observer-based DC voltage droop and current feed-forward control of a DC microgrid. IEEE Trans. Smart Grid 2017, 9, 5207-5216. [CrossRef]

30. Hosseinzadeh, M.; Salmasi, F.R. Power management of an isolated hybrid AC/DC micro-grid with fuzzy control of battery banks. IET Renew. Power Gener. 2014, 9, 484-493. [CrossRef]

31. Erickson, R.W.; Maksimovic, D. Fundamentals of Power Electronics; Springer Science \& Business Media: New York, NY, USA, 2001.

32. Zhi, N.; Zhang, H.; Li, N.; Yang, J. System-level design and stability analysis of DC microgrid. In Proceedings of the International Power Electronics and Application Conference and Exposition, Shanghai, China, 5-8 November 2014; pp. 1134-1137.

33. Wildrick, C.M.; Lee, F.C.; Cho, B.H.; Choi, B. A method of defining the load impedance specification for a stable distributed power system. IEEE Trans. Power Electron. 1995, 10, 280-285. [CrossRef]

34. Feng, X.; Liu, J.; Lee, F.C. Impedance specifications for stable DC distributed power systems. IEEE Trans. Power Electron. 2002, 17, 157-162. [CrossRef]

35. Sudhoff, S.D.; Glover, S.F.; Lamm, P.T.; Schmucker, D.H.; Delisle, D.E. Admittance space stability analysis of power electronic systems. IEEE Trans. Aerosp. Electron. Syst. 2000, 36, 965-973. [CrossRef]

36. Feroldi, D.; Degliuomini, L.N.; Basualdo, M. Energy management of a hybrid system based on wind-solar power sources and bioethanol. Chem. Eng. Res. Des. 2013, 91, 1441-1455. [CrossRef] 